\title{
Regulation of Ras exchange factors and cellular localization of Ras activation by lipid messengers in T cells
}

\author{
Jesse E. Jun ${ }^{1}$, Ignacio Rubio ${ }^{2}$ and Jeroen P. Roose ${ }^{1 *}$ \\ 1 Department of Anatomy, University of California San Francisco, San Francisco, CA, USA \\ 2 Institute for Molecular Cell Biology, Center for Sepsis Control and Care (CSCC), University Hospital, Friedrich-Schiller-University, Jena, Germany
}

\section{Edited by:}

Karsten Sauer, The Scripps Research Institute, USA

\section{Reviewed by:}

Kjetil Taskén, University of Oslo, Norway

Balbino Alarcon, Consejo Superior de Investigaciones Cientificas, Spain

\section{*Correspondence:}

Jeroen P. Roose, Department of

Anatomy, University of California San Francisco, 513 Parnassus Avenue,

Room HSW-1326, San Francisco, CA 94143-0452, USA

e-mail: jeroen.roose@ucsf.edu
The Ras-MAPK signaling pathway is highly conserved throughout evolution and is activated downstream of a wide range of receptor stimuli. Ras guanine nucleotide exchange factors (RasGEFs) catalyze GTP loading of Ras and play a pivotal role in regulating receptorligand induced Ras activity. InT cells, three families of functionally important RasGEFs are expressed: RasGRF, RasGRP, and Son of Sevenless (SOS)-family GEFs. Early on it was recognized that Ras activation is critical for T cell development and that the RasGEFs play an important role herein. More recent work has revealed that nuances in Ras activation appear to significantly impact T cell development and selection. These nuances include distinct biochemical patterns of analog versus digital Ras activation, differences in cellular localization of Ras activation, and intricate interplays between the RasGEFs during distinct T cell developmental stages as revealed by various new mouse models. In many instances, the exact nature of these nuances in Ras activation or how these may result from fine-tuning of the RasGEFs is not understood. One large group of biomolecules critically involved in the control of RasGEFs functions are lipid second messengers. Multiple, yet distinct lipid products are generated following T cell receptor (TCR) stimulation and bind to different domains in the RasGRP and SOS RasGEFs to facilitate the activation of the membrane-anchored Ras GTPases. In this review we highlight how different lipid-based elements are generated by various enzymes downstream of the TCR and other receptors and how these dynamic and interrelated lipid products may fine-tune Ras activation by RasGEFs in developing $T$ cells.

Keywords:T cell, signaling, lipids, Ras, SOS, RasGRP, LAT, P38

\section{NON-ONCOGENIC Ras ACTIVATION FIRST OBSERVED IN T LYMPHOCYTES}

Ras is a membrane-bound small GTPase that plays a pivotal role in transducing responses to diverse extracellular signals that impact various cellular processes, prominently cell proliferation, differentiation, apoptosis (1). Ras cycles between a GTP-associated active state (Ras.GTP) and GDP-bound inactive state (Ras.GDP). In both the Ras.GDP and Ras.GTP states the nucleotide is very tightly bound (2-4) and for Ras activation to occur Ras guanine nucleotide exchange factors (RasGEFs) need to loosen the grip of Ras on the bound nucleotide, stabilizing nucleotide-free Ras that stochastically but preferentially associates with GTP, because GTP is present in the cell in higher concentrations than GDP (5). Reciprocally, GTP hydrolysis is critical for inactivation from Ras.GTP to Ras.GDP and Ras' modest intrinsic rate of GTP hydrolysis requires the hydrolysis-augmenting action of RasGAPs (Ras GTPase activating proteins) (Figure 1).

The physiological importance of Ras' GTPase activity was recognized in the late 80s through the detection and biochemical characterization of GTPase impairing Ras mutations commonly found in various human tumor tissues (6). Ras.GTP is a potent signaling hub, connecting to many downstream effector molecules like RAF, PI3K, and RalGDS. The best-characterized signaling cascade is the Ras-GTP-RAF-MEK-ERK pathway $(4,7,8)$.
In cells without mutations in Ras only a small portion of the total amount of Ras is GTP-loaded following receptor stimuli, which makes detection more challenging. In the early 90s Doreen Cantrell's group first showed Ras activation (or Ras.GTP loading) in normal $\mathrm{T}$ lymphocytes that were stimulated with the interleukin 2 (IL2) cytokine or a phorbol ester, agents that were known to induce lymphocyte proliferation $(9,10)$. The physiological significance of biochemical signals transduced by an intact Ras-RAF-MEK-ERK pathway in lymphocytes was subsequently shown through transgenic expression of mutant Ras- and MEK-alleles in thymocytes; for example, expression of dominantnegative $\mathrm{H}-\mathrm{Ras}^{\mathrm{S}}{ }^{\mathrm{N} \mathrm{N}}$ under the control of $l c k$ promoter or catalytically inactive MEK-1 perturbs positive selection of developing thymocytes $(11,12)$.

Research over the past two decades has revealed many intricate ways of regulated Ras activation, not only in lymphocytes but also in other cell types. In this review we will discuss the role of lipid messengers in regulating the Son of Sevenless (SOS) and RasGRP RasGEF families. We will focus on recent findings related to lipid-RasGEF regulation, recent insights from novel mouse models, as well as on the ongoing debate of the cellular compartment or location of Ras activation. For additional information on the RasGEF family of exchange factors we refer to previous review articles $(8,13-15)$. 


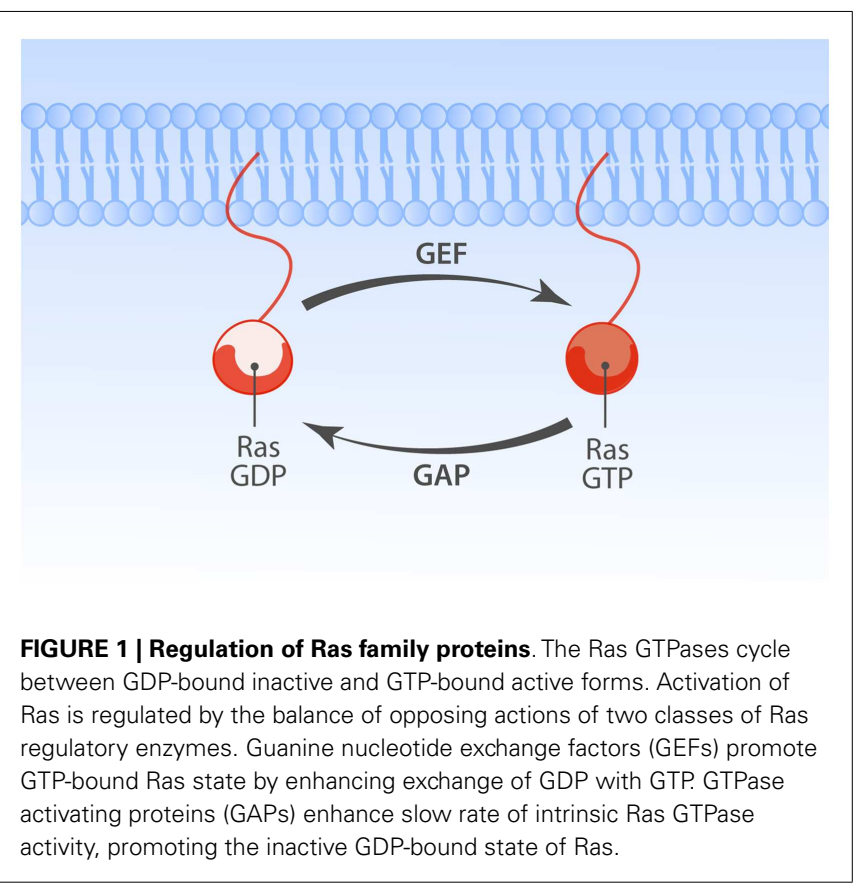

\section{THE PLAYERS; THREE FAMILIES OF Ras GUANINE NUCLEOTIDE EXCHANGE FACTORS}

The earlier-mentioned dominant-negative Ras approach established a critical role for Ras in lymphocytes. Data from numerous laboratories have meanwhile demonstrated that dominantnegative Ras ${ }^{\mathrm{S} 17 \mathrm{~N}}$ exerts its blocking action mainly by usurping and blocking RasGEFs [although other features of Ras ${ }^{\mathrm{S} 17 \mathrm{~N}}$ probably contribute to its inhibitory action $(16,17)]$. Thus, the ability of dominant-negative Ras ${ }^{\mathrm{S} 17 \mathrm{~N}}$ to affect lymphocyte biology not only highlights the importance of Ras but points also to a critical role of GEFs.

If we fast-forward roughly two decades, we now know that lymphocytes can simultaneously express three types of RasGEF proteins (Figure 2). The overlapping expression profiles create the impression of seemingly redundant and unnecessary complex mechanisms to couple antigen receptor stimulation to Ras activation. However, distinct lymphocyte developmental defects in mice deficient for unique RasGEFs argue for specialized functions for each RasGEF (18-20). We will cover the mouse phenotypes in more detail in subsequent paragraphs and will first focus on the different protein domains in the three RasGEF families [also reviewed in Ref. $(5,8)]$.

\section{SON OF SEVENLESS}

There are two members in SOS-family RasGEFs, SOS1 and SOS2. Structurally, the SOS protein is composed of six domains that have distinct functional importance: starting from the $\mathrm{N}$-terminus, the histone-like fold (HF), the Dbl homology domain (DH), the Pleckstrin homology $(\mathrm{PH})$ domain, the Ras exchange motif (REM), the Cdc25 homology domain, and the proline-rich (PR) domain (Figures 2 and 3 ). The naming of HF comes from structural resemblance to histone 2 dimer $\mathrm{H} 2 \mathrm{a}-\mathrm{H} 2 \mathrm{~b}$, and HF mediates lipid interaction with phosphatidylinositol 4,5-bis phosphate $\left[\mathrm{PI}(4,5) \mathrm{P}_{2}\right.$,

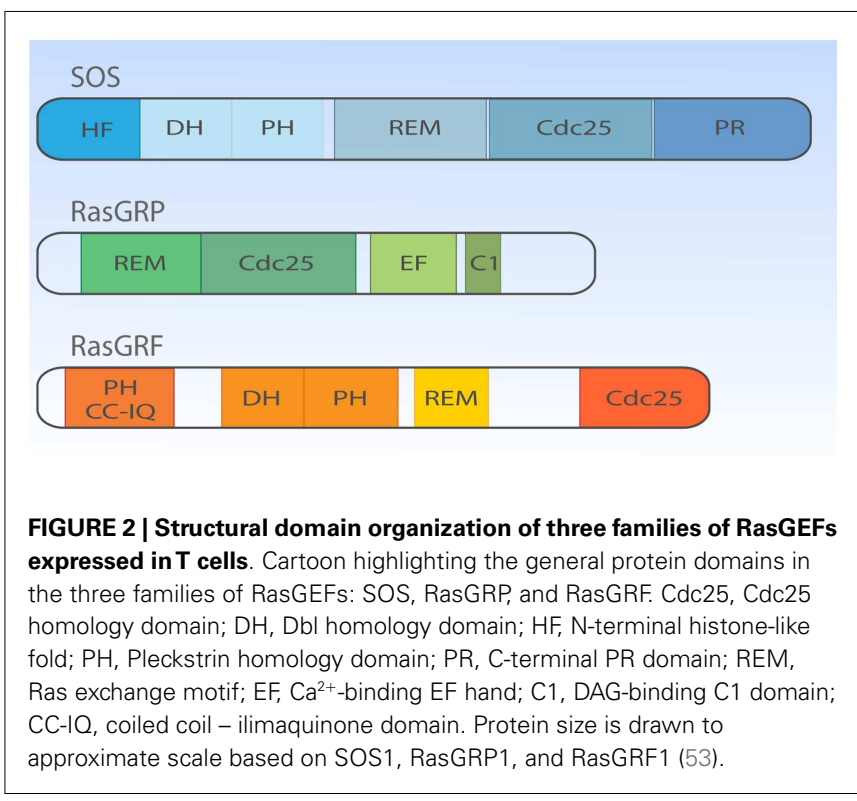

hereafter $\mathrm{PIP}_{2}$ ] or phosphatidic acid (PA) (21). The DH domain is a functional domain commonly found in Rho family GEFs, suggesting SOS may also have Rho-specific GEF function in addition to the more established RasGEF activity $(22,23)$. PH domains are lipid/protein-interacting domains (24). The PH domain of SOS has an auto-inhibitory function, that is regulated by interaction with membrane lipids such as PIP $_{2}$ or PA (25-29). REM-Cdc25 domains make up the RasGEF catalytic core of SOS and all other RasGEFs. Unique to SOS, its catalytic core contains two distinct Ras-binding sites: one for GDP/GTP exchange and the other for allosteric regulation of SOS by Ras $(30,31)$. The C-terminal PR domain is the only segment of SOS that remains to be structured for analysis. Functionally, the PR domain contains multiple PR motifs that can bind $\mathrm{SH} 3$ domain-containing proteins such as the SH2-SH3-SH2 adapter Grb2 $(32,33)$, the $\mathrm{p} 85$ subunit of PI3kinase (34), PLC $\gamma 1$ (35-38), and Avi1/E3b1 (39). In addition, the PR domain contains multiple documented phosphorylation sites of ERK and probably other kinases (40-44), spiked in between the PR stretches that are, at least in part, postulated to play a role in feedback control of SOS activity.

\section{RAS GUANINE NUCLEOTIDE RELEASING PROTEINS}

Much less is known about the function of the domains or even the identity of domains in the RasGRP RasGEFs. To date, there is no RasGRP structure and we are therefore limited to make predictions based on amino acid sequence. There are four RasGRP proteins, RasGRP-1 through RasGRP-4, with specific expression profiles and nuances in biochemical function. All RasGRP's contain a central catalytic core consisting of the catalytic REM-Cdc25 cassette. Sequence divergency between the RasGRP and SOS REM-Cdc25 cores predicts that RasGRPs are not regulated through an allosteric activation mechanism. Although RasGRP2 contains the REMCdc25 core and early studies indicated RasGEF activity (45), it is generally accepted that RasGRP2 functions as a GEF for the small GTPase Rap (46). Analogously, all four proteins are predicted to have a $\mathrm{C} 1$ domain positioned $\mathrm{C}$-terminal of the catalytic core, but 

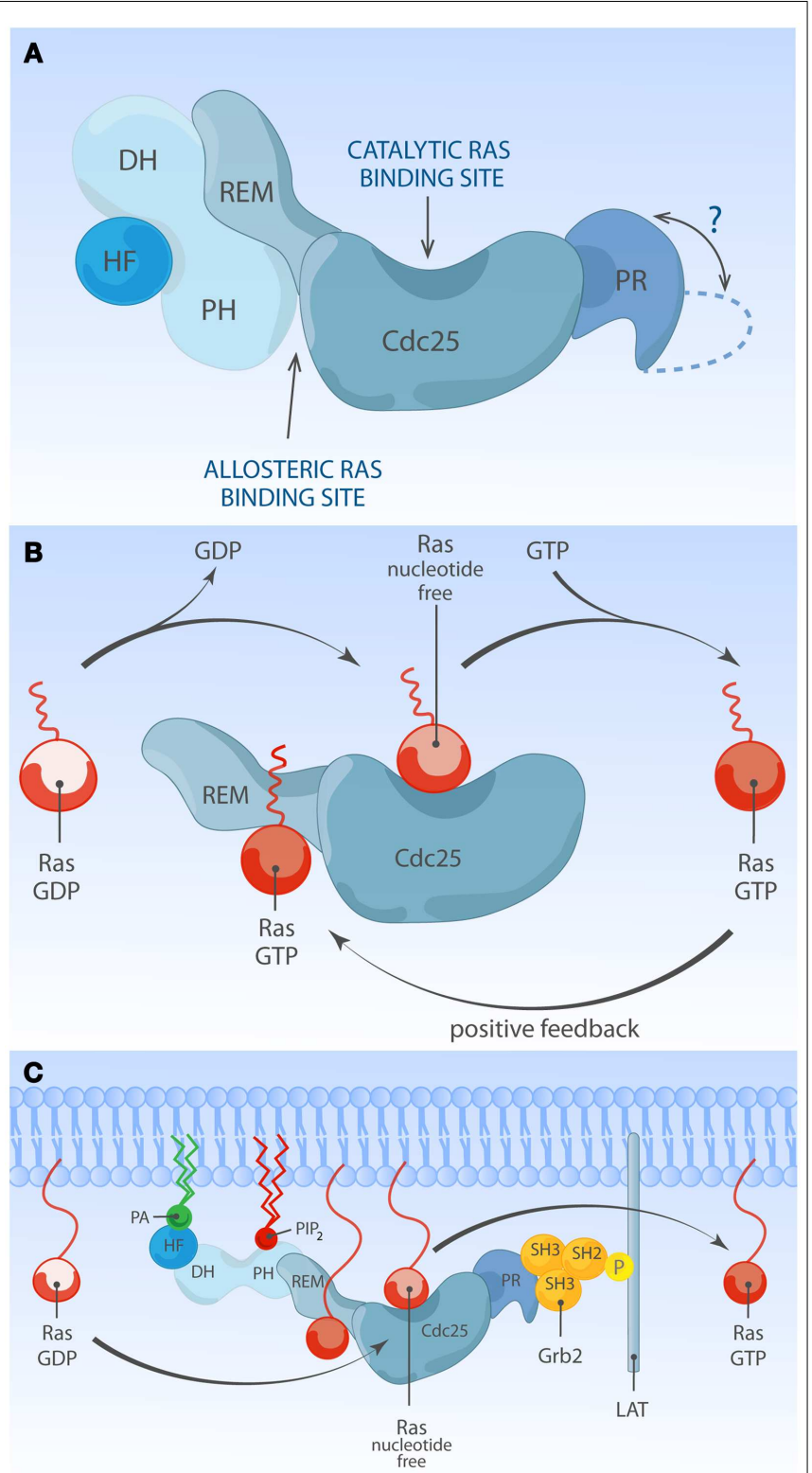

FIGURE 3 | Multiple membrane-derived signals determine the RasGEF activity of SOS. (A) Model of inactive SOS. In the inactive state, SOS'S $\mathrm{DH}-\mathrm{PH}$ domains obscure the allosteric Ras-binding pocket. Without engagement of the allosteric pocket by Ras.GTP, SOS only shows low reactivity for Ras.GDP at the catalytic binding site. The HF docks itself to a helical linker region (not depicted) between PH and REM domains, further stabilizing auto-inhibited state of SOS. The protein structure of the C-terminal proline-rich domain has not been determined to date. (B) Model of allosteric activation of SOS. Ras.GTP binding to the allosteric site enhances SOS exchange activity by increasing Ras-binding affinity for the catalytic pocket, establishing a positive feedback mechanism. Other SOS domains are omitted for simplicity. (C) Model of full activation of SOS. Full activation of SOS requires the integration of multiple membrane-derived signals. Grb2-mediated membrane recruitment of SOS to phosphorylated LAT is thought to be one of the initial membrane recruitment mechanisms. Membrane phospholipids such as $\mathrm{PIP}_{2}$ and $\mathrm{PA}$ interact with $\mathrm{HF}$ and $\mathrm{PH}$ domains, and these interactions further relieve auto-inhibition state of SOS, allowing efficient access of Ras to both the allosteric and catalytic sites. again, RasGRP2 appears to be most divergent in that its $\mathrm{C} 1$ domain does not bind diacylglycerol (DAG) (47) and RasGRP2 protein does not translocate to the membrane when cells are stimulated with DAG analogs (48). A third shared domain in all RasGRP proteins is the pair of $\mathrm{EF}$ hands that occupies an interesting position in the protein, sandwiched between the catalytic core and the $\mathrm{C} 1$ domain (Figures 2 and $\mathbf{4}$ ). EF hands typically come in pairs with each hand binding one calcium ion $(49,50)$. However, not all EF hands bind calcium. For instance, RasGRP1 with two predicted $\mathrm{EF}$ hands based on the amino acid sequence can only bind one calcium ion with one EF hand, not with both (51). Close examination of the sequence similarities and divergence in the EF hand domains of all RasGRP proteins (not shown) tells us that there are likely going to be substantial differences in the ways that the different RasGRP's are regulated by calcium. Thus, the four RasGRP proteins demonstrate specific biochemical regulatory mechanisms and activities that have likely evolved over time to establish their individual exchange functions in the specific cell types where they are expressed. In this review we will not cover the differences between the RasGRPs in much more detail, instead we refer you to an excellent review by Stone (15) and one on cancer (52).

\section{RAS GUANINE NUCLEOTIDE RELEASING FACTOR}

More closely related to SOS than RasGRP are RasGRF's; RasGRF1 and RasGRF-2 make up this family of proteins with multiple domains [reviewed in Ref. (53)]. Similar to the two other RasGEF family proteins, RasGRF proteins contain a REM-CDC25 catalytic core domain. Uniquely, RasGRFs contain two PH domains; one at the $\mathrm{N}$-terminus ( $\mathrm{PH} 1$ ) and the other $\mathrm{PH}$ in tandem with the $\mathrm{DH}$ domain $(\mathrm{PH} 2)$, similar to the configuration of the $\mathrm{DH}-\mathrm{PH}$ domain of SOS-family proteins (Figure 2). PH1 cooperates to promote stimulation-dependent membrane localization of RasGRF in fibroblasts, probably through interaction with membrane lipid (53-55). The coiled-coil (CC) domain is known to mediate protein oligomerization (56), whereas the ilimaquinone (IQ) domain mediates calmodulin binding (57). In cooperation with the PH1 domain, CC and IQ domains notably mediate the interaction with a MAPK p38 scaffold protein IB2/JIP2 in COS7 cells (58), which is interesting because the DH-PH domain of RasGRF has GEF activity toward $\operatorname{Rac}(59,60)$ indicating that RasGRF may efficiently link Rac to the p38 pathway through the IB2/JIP2 scaffold protein (58).

\section{EXPRESSION PATTERNS OF THE EIGHT RASGEF GENES}

The RasGRP and RasGRF families of exchange factors have tissuespecific expression patterns whereas SOS proteins are ubiquitously expressed (15). For instance, RasGRP1 is expressed in dynamic patterns in developing $\mathrm{T}$ cells $(20,61)$, in the brain (46), and in primary keratinocytes (62). RasGRF1 and RasGRF2 are predominantly expressed in the central nervous system (63). In addition, RasGRF2, but not RasGRF1, is expressed in T cells (64). Analyses of rasgrf2-deficient mice revealed that this RasGEF play a critical role in the activation of NFAT target genes in T cells (64). However, $\mathrm{T}$ cell development is normal in Rasgrf2 $2^{-1-}$ mice, and Rasgrf2 appears to have only limited activity toward Ras-ERK in T cells (64). We will therefore limit ourselves to the regulation of SOS and RasGRP here. Significantly, these two distinct types of RasGEFs cooperate to establish robust yet controlled activation of Ras 

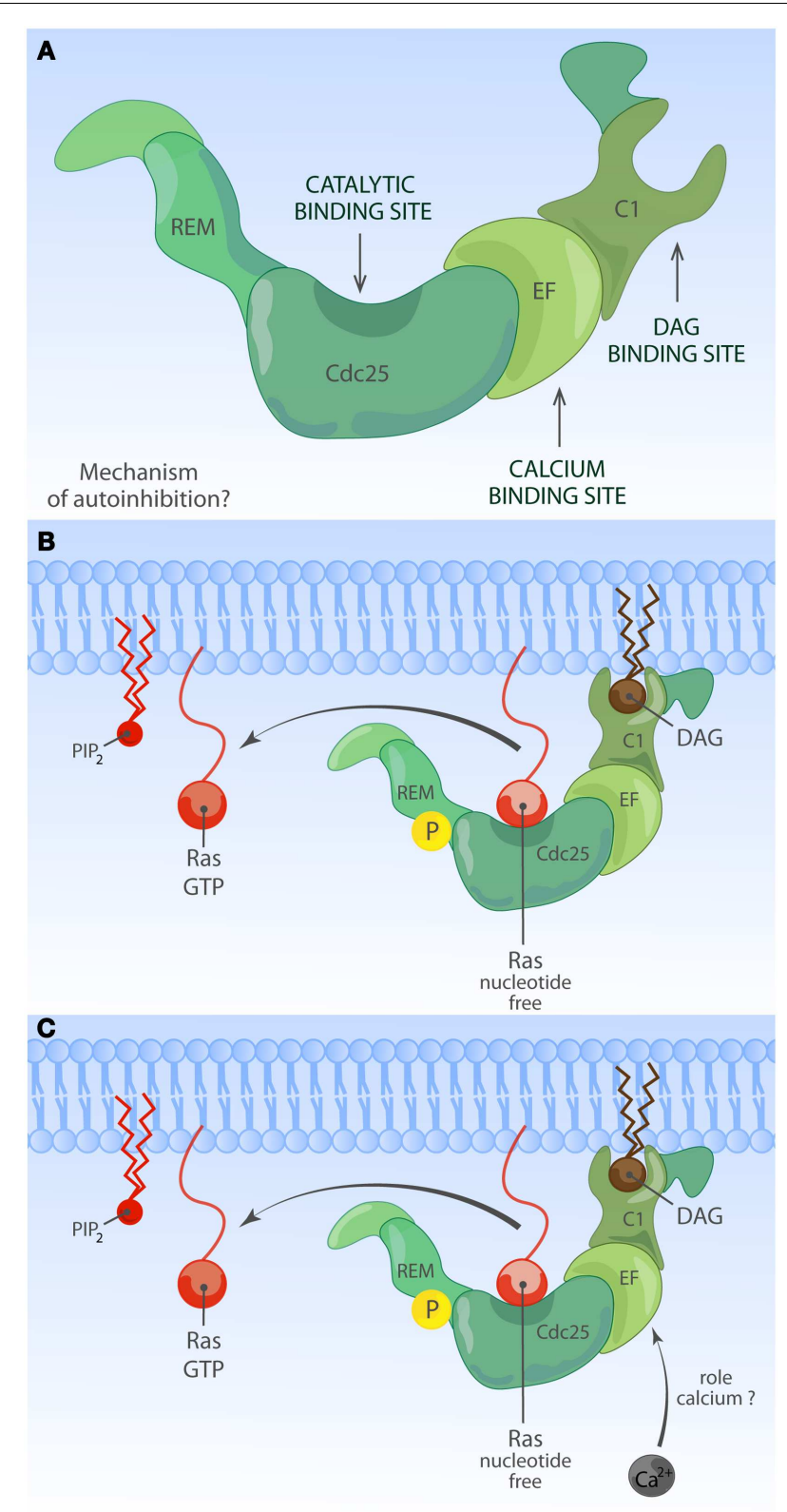

FIGURE 4 | Activation of RasGRP. (A) Depiction of RasGRP with its protein domains. RasGRPs must be controlled to prevent spurious Ras activation but the exact mechanism of auto-inhibition is unknown. Roles for various domains C-terminal of the Cdc25 domain to limit membrane recruitment of RasGRP have been proposed. (B) DAG-regulated membrane recruitment of RasGRP. Receptor-induced generation of diacylglycerol (DAG) results in efficient membrane recruitment on RasGRP1, RasGRP3, and RasGRP4 where these RasGEFs can encounter Ras.GDP to activate it to Ras.GTP. RasGRP1 and RasGRP3 are known to be phosphorylated on a conserved threonine residue at the very start of the $\mathrm{Cdc} 25$ domain, which enhances their catalytic activity through an unknown mechanism. RasGRP2 does not efficiently bind DAG and must have a different membrane-recruiting mechanism. (C) Other regulatory mechanisms for RasGRP. Amino acid sequence homologies predict that RasGRPs lack and allosteric Ras-binding pocket as the one observed for SOS. RasGRP proteins contain EF hands, structure that can often bind calcium. Calcium has been implicated in the recruitment of RasGRP1 to the membrane but nuances appear to exist in different cell types. It is not known if other lipid moieties such as $\mathrm{PIP}_{2}$ can regulate the activity or residence time of RasGRP1 at the membrane. and Ras' RAF-MEK-ERK effector pathway $(65,66)$. In response to $\mathrm{T}$ cell receptor (TCR) stimulation, both RasGRP1 and SOS are recruited to the membrane where they encounter membraneanchored Ras and both convert Ras.GDP to Ras.GTP. Why is it then that knockout mouse models for SOS1 and RasGRP1 show different impairments in terms of thymocyte selection and $\mathrm{T}$ cell development $(20,61,67)$ ?

\section{AUTO-INHIBITION OF SOS RasGEFs}

Ample structural and cellular studies indicate that catalytic activity of SOS1 is self-limited by an intramolecular auto-inhibitory mechanism which involves multiple internal protein domains. Autoinhibition can be relieved by membrane signals from proteins and lipid species. The physiological relevance of auto-inhibition of SOS1 is highlighted by a clinical condition called Noonan syndrome (NS). NS is a relatively common autosomal developmental abnormality and RASopathy, a disease that is caused by germline mutations in molecules leading to modestly increased Ras signaling $(68,69)$. NS is genetically heterogeneous: the majority of mutations are associated with PTPN11, K-Ras, N-Ras, SOS1, B-Raf, Raf-1, SHOC1, and CBL (69). Among eight NS-associated genes, missense mutations in SOS1 are identified in about $10 \%$ of NS cases (69-73). Most NS-associated SOS1 mutations are predicted to relieve auto-inhibiting structural constraints within SOS1, allowing increased signal output through the Ras pathway. Indeed, several NS-associated SOS1 mutant alleles (R552G, E108K, W729L, and E846K) have been experimentally characterized in vivo, showing increased Ras.GTP accumulation and ERK activation at basal state or upon stimulation $(70,71,74,75)$. These findings visibly illustrate that normal SOS1 function is tightly regulated and highlight the clinical relevance of such regulation (Figure 3A). These observed defects in fine-tuning of Ras activity control in NS cells are also likely to impact on the patient's immune biology, because patients with gain-of-function mutations in Ras proteins are at a higher risk of developing autoimmune disorders (76-79). In the following few sections, we will review the literature on normal SOS regulatory mechanisms and how membrane-based signals from proteins and phospholipids influence the activation status of SOS.

\section{MEMBRANE RECRUITMENT OF SOS BY Grb2: INITIAL STEP IN SOS ACTIVATION}

$\mathrm{T}$ cell receptor stimulation leads to rapid activation of Src family kinases and the Syk family kinase ZAP70. ZAP70 phosphorylates the adapter LAT, a key scaffold to which various downstream signal transducers are assembled, including molecules that are coupled to Ras-MAPK pathway activation (80). Prior to cell stimulation, most SOS is found in the cytoplasmic compartment, constitutively bound to the $\mathrm{SH} 3-\mathrm{SH} 2-\mathrm{SH} 3$ domain-containing adapter Grb2. Upon stimulation, SOS rapidly localizes to the plasma membrane (PM) $(32,33,81,82)$. SOS1 membrane targeting is an essential event for SOS-Ras activation and is mediated by binding of the $\mathrm{SH} 2$ domain of Grb2 (with SOS1) to phosphorylated tyrosine residues of LAT (82). A truncated SOS1 variant incapable of Grb2 binding is still functional as a RasGEF but can activate Ras only if targeted elsewise to the membrane, indicating that membrane recruitment is an essential step in ligand-dependent activation of SOS (83). Unlike Ras, lipid modification of SOS was never been reported. 
Therefore, Grb2-mediated membrane anchorage has been viewed as the key regulatory mechanism of SOS GEF signal output.

However, the traditional view that Grb2 association is dominant or even essential for SOS1 membrane targeting has also been challenged. Expression of C-terminally truncated SOS1 incapable of Grb2 binding has been documented to have comparable or even better Ras-ERK signal responses compared to full-length SOS1 (84-86). Similarly, $\operatorname{SOS}^{\Delta \mathrm{C}}$, a C-terminally truncated SOS mutant lacking residues 1050-1333 becomes recruited to the membrane in response to serum stimulation, indicating that Grb2 is not the only mechanism for ligand-dependent SOS1 membrane targeting (29). These studies may collectively imply that Grb2 is a redundant mechanism for stimulation-dependent SOS membrane localization and subsequent SOS activation. However, little attention is given to the physiological relevance of the protein levels of the C-terminal truncated SOS1 variant examined in these studies and time kinetics of Ras-ERK response. It is very plausible that Grb2 is important and a major membrane anchorage mechanism when physiological levels of SOS1 are available to the activated ligand. Supporting this notion, structural studies and recent mouse embryonic stem cell (mESC) study demonstrate that, besides Grb2-mediated membrane recruitment, the SOS1 activity is determined by summation of weak to moderate membrane protein and lipid interactions mediated by multiple protein domains of SOS1 (87).

\section{ALLOSTERIC ACTIVATION OF SOS; A POSITIVE FEEDBACK LOOP}

The SOS1-mediated nucleotide exchange rate on Ras is 500-fold higher when Ras is membrane-bound compared to when Ras activation is measured in solution (88), supporting a view that ligand-dependent membrane recruitment of SOS1 not only exists to promote the chance of substrate encounter but is also instrumental to enhance SOS1 enzymatic activity. One hint for the existence and identity of additional membrane signals regulating SOS1 came from structural studies by the Bar-Sagi and Kuriyan groups. Unexpectedly SOS1 was found to be associated with two discrete Ras molecules, forming a 2:1 ternary complex between two Ras molecules and one SOS1 molecule. One Ras molecule serves as a substrate and is bound at its catalytic pocket within the Cdc25 domain, while the second non-substrate Ras occupies the allosteric site in the REM domain (31). Occupation of the allosteric site by Ras.GTP results in conformational change stabilizing SOS1 catalytic pocket and stimulates in vitro nucleotide exchange activity by $\sim 75$-fold $(89,90)$. In support of this notion, a SOS1 mutant unable to bind to Ras at allosteric site (W729E) shows reduced affinity for Ras at the catalytic site and has low in vitro activity (89). The allosteric Ras-binding pocket shows 10-fold higher affinity for GTP-loaded Ras than Ras-GDP. This preferential affinity for Ras.GTP endows SOS1 to sense the activation status of Ras at the membrane and establishes a positive feedback regulation (Figure 3B) $(31,91)$. Ectopic expression studies provided in vivo evidence of allosteric regulation of SOS1 in COS-1 cells $(89,91)$ or Jurkat cells $(65,66)$. Recently, allosteric mutant-SOS1 reconstitution into SOS-deficient mESC (87) and DT40 B cells (92) provided more definitive proof of allosteric SOS1 activation regulating the output through the Ras-ERK pathway. In addition to enhancing catalytic activity of SOS, allosteric Ras.GTP binding could potentially affect SOS residence time at the PM by providing an additional membrane anchor for SOS1 other than Grb2 binding.

\section{REGULATION OF SOS BY MEMBRANE LIPIDS}

Current evidence argues that allosteric Ras binding to SOS1 is such a pivotal step that SOS stays inactive unless Ras.GTP is bound at the allosteric site (93). Then, how has SOS1 evolved to limit spontaneous signaling yet allow for controlled allosteric activation near the membrane interface? In this regard, N-terminal SOS domains play a critical role in regulating SOS1 activation in the context of membrane proximity by sensing membrane lipids.

One membrane lipid sensing N-terminal regulatory unit is the tandem $\mathrm{DH}$ and $\mathrm{PH}$ domain. In vitro and in vivo studies identified DH-PH domain being important for membrane-proximal SOS regulation $(29,84,87,93)$. DH domain is commonly found with GTP exchange factors (discussed later). In SOS, the DH domain serves as a gatekeeper preventing promiscuous access to the allosteric Ras-binding pocket. In its auto-inhibited state, SOS1 DH domain blocks the allosteric pocket from Ras binding, which has a critical impact on SOS1's catalytic pocket. Without allosteric activation the catalytic pocket is not fully receptive to accommodate Ras.GDP and the helical hairpin of SOS1 is not in the correct orientation to dislodge GDP from $\operatorname{Ras}(89,93)$. $\mathrm{PH}$ domain is generally known for protein or lipid interactions (55). The PH domain of SOS1 was shown to have affinity for $\mathrm{PIP}_{2}$ (25-28) or PA (29). The auto-inhibiting $\mathrm{DH}$ domain can be released by electrostatic interaction of membrane $\mathrm{PIP}_{2}$ or PA with positively charged residues within the $\mathrm{PH}$ domain $(29,93)$. Therefore, lipid-DH$\mathrm{PH}$ interactions facilitate re-orientation of SOS1 at the membrane interface, allowing allosteric Ras binding (Figure 3C). In support, addition of cell-permeable PA to COS-1 cells is sufficient to induce GTP loading of Ras, and charge-inversion mutations of $\mathrm{H} 475 \mathrm{E}$ and R479E in SOS1 abolish PA interaction and PA-induced Ras.GTP loading response (29). Similarly, two different basic residues (K456 and $\mathrm{R} 459$ ) within the $\mathrm{PH}$ domain interact with $\mathrm{PIP}_{2}$ (93). The biological significance of $\mathrm{PIP}_{2}-\mathrm{PH}$ domain interaction during $\mathrm{mESC}$ differentiation was elegantly demonstrated in a recent report from Tony Pawson's group (87).

Located upstream of DH-PH domains, the HF is an evolutionarily conserved segment (residue 1-191) resembling dimerized histone (21). Based on structural studies, this HF docks itself into the helical linker region of SOS1, located between DH-PH domains and catalytic segment (REM-Cdc25), ensuring SOS autoinhibition by blocking allosteric activation and by stabilizing a closed conformation of SOS $(88,94)$. HF interacts with membrane lipids such as $\mathrm{PA}$ and $\mathrm{PIP}_{2}$, and HF-lipid interaction reverses autoinhibitory docking, allowing allosteric and catalytic Ras binding at distal and proximal Ras-binding sites $(75,88)$. Electrostatic charge distribution at the phospholipid-interacting interface of HF appears to be finely tuned by charge neutralization, e.g., the negatively charged residue E108 is surrounded by patches of basic residues (75). Disturbing charge balance by offsetting positive charges leads to reduced Ras-ERK activation in COS-1 and mouse ES cells $(75,87)$. Additionally, a negative charge neutralization mutation $(\mathrm{E} 108 \mathrm{~K})$ is found to be associated with a hyperactive SOS1 allele of human NS $(71,75)$. 
There are some inconsistencies in the lipid species recognized by SOS1's N-terminal regulatory domains $(29,75,88,93)$. This discrepancy might arise from the variability in the presence of regulatory domains or post-translational modifications of the SOS1 proteins investigated. Perhaps more significant, membrane lipids are also dynamically regulated during cell activation processes (reviewed in Krishna and Zhong (95) in this Research Topic and by Sauer and Cooke (96)). Perhaps, the reported discrepancies regarding the role of lipid species may reflect heterogeneous lipid patterns in distinct cellular backgrounds and the involvement of different lipids at different stage of SOS1 activation.

Taken together, studies in vitro and in vivo support the view that N-terminal HF and DH-PH domains serve as membrane lipid sensing regulatory segments. On one hand, lipid mediated regulation of SOS1 leads to juxtaposition of SOS1 to substrate/effector. On the other hand, the regulatory domains also contribute to prevent spontaneous activation of SOS1. In this regard, it is worth noting that the second class of human NS-associated SOS1 mutations target $\mathrm{N}$-terminal regulatory domains and often implicate enhanced membrane recruitment of the mutant SOS protein (73).

\section{RasGRP AUTO-INHIBITION?}

RasGRP proteins have been studied most extensively in T- and B-lymphocytes. In these lymphocytes, RasGRP1 and RasGRP3 activate Ras in a manner that is non-redundant with SOS (18, 65, 97-101). More recently, RasGRP proteins, particularly RasGRP1, have also been associated with human diseases such as autoimmune disease and cancer.

Single nucleotide variants near RASGRP1 are associated with susceptibility to autoimmune (Type 1) diabetes and to thyroid autoantibodies in Graves disease $(102,103)$. At this point it is not known what effect these variants in non-coding regions of the RasGRP1 gene have, but possible mechanisms include altered expression or RasGRP1. RASGRP1 splice variants have been documented for patients with systemic lupus erythematosus (SLE) (104). Several of these RasGRP1 mRNA splice variants are predicted to miss portions of RasGRP1's EF hands, which may have an important regulatory role (see below). In addition, it also appeared that many splice variants resulted in lower proteins expression levels of RasGRP1 (104).

RasGRP4 was originally isolated as a Ras activator in acute myeloid leukemia (AML) (105). RasGRP3 plays a role in human melanoma (106) and in prostate cancer (107) that are distinct from those of SOS. When overexpressed from transgenes, RasGRP1 promotes the development of squamous cell carcinoma and melanoma in mouse models in conjunction with skin wounding or carcinogen painting of the skin (108-110). Transgenic over-expression of RasGRP 1 in developing $\mathrm{T}$ lymphocytes causes thymic lymphomas in mice (111) and several unbiased mouse model screens for leukemia genes have identified the RasGRP1 locus as a hot-spot for leukemia virus integrations driving blood cancer (112-114). The molecular basis of these viral integrations is that these cause leukemia through the dysregulated expression of the target gene, typically through overexpression. Significantly, Oki and colleagues as well as our own group have recently shown that elevated RasGRP1 expression also occurs in T cell leukemia patients $(115,116)$. For more detailed reading on RasGRP1's role in cancer we refer you to a different review (52). Needless to say these studies collectively indicate that RasGRP1 requires tight regulation. Regulation occurs most definitely at the level of RasGRP1 expression since dysregulated expression of a wild-type RasGRP1 form results in leukemia (116). Extrapolating from our knowledge of SOS1, we propose that RasGRP1 also possesses an auto-inhibited state (Figure 4A) to prevent spurious activation and to balance the activating mechanisms of molecules like DAG, which we will discuss next.

\section{DIACYLGLYCEROL AS A RasGRP1 ACTIVATOR}

Phorbol esters such as PMA (a synthetic DAG analog produced out of the plant-derived compound phorbol) had long been known as potent stimulators of Ras activation, but it was not until 1998 when Stone and colleagues cloned the RasGRP1 gene, that the biochemical connection between DAG and Ras activation was established (51).

In $\mathrm{T}$ lymphocytes that receive a TCR stimulus, PLC $\gamma 1$ is recruited to the membrane and activated so that it cleaves $\mathrm{PIP}_{2}$ into inositol-3-phosphate $\left(\mathrm{IP}_{3}\right)$ and DAG. IP3 couples to the calcium pathway (117) and we will come back to this in a moment. The increase of DAG levels in the membrane results in recruitment of RasGRP1 through its C1 domain to the membrane where is can activate Ras (Figure $4 \mathbf{B})(19,51)$. There is a second, indirect route from DAG to RasGRP1 and RasGRP3, which involves PKC-mediated phosphorylation of these two RasGEFs. RasGRP1 is phosphorylated on threonine 184 (T184) in TCR-stimulated T cells whereas RasGRP3 is phosphorylated on the analogous site, T133, in BCR-stimulated B cells $(97,100,118)$. Mutations of T184 or T133 into alanine residues results in impaired, but not absent, stimulus-dependent Ras activation $(97,118)$ and incubation of cells with PKC inhibitors blocks the phosphorylation of RasGRP1 on $\mathrm{T} 184(65,97,100)$, providing a rationale for the long established observation that PKC inhibition inhibits the output through the Ras-ERK pathway in lymphocytes. How the phosphorylation of RasGRP1 and RasGRP3 enhances their RasGEF activity is not known.

Because of DAG's prominent role in RasGRP1 and RasGRP3 activation in T- and B-lymphocytes, generation of DAG by PLC $\gamma$ enzymes, and turnover by DAG kinases (DGKs) should be considered. In agreement with a PLC $\gamma 1-D A G-R a s G R P 1$ signaling axis (Figure 5), conditional PLC $\gamma 1$ knockout mice and RasGRP1deficient mice share a similar defect in positive selection of thymocytes and ERK activation $(18,119)$. On the other side of the cycle, DGK's convert DAG to PA, which is interesting because this would dampen DAG-RasGRP signals but perhaps promote PA-SOS signals. In agreement with a critical role for DGK in dampening RasGRP activity (as well as the activity of other proteins containing DAG-binding C1 domains), deletion of DGK $\alpha$ and DGK $\gamma$ results in increased incidence of T cell lymphoma (120). In normal T cells, DGK enzymes play a critical role in controlling the balance between activation and anergy or unresponsiveness $(121,122)$. For a complete review of DAG metabolism and the role of DGK enzymes we refer to Krishna and Zhong (95) in this Research Topic. The role of DAG in RasGRP1 regulation is obvious but may not be 


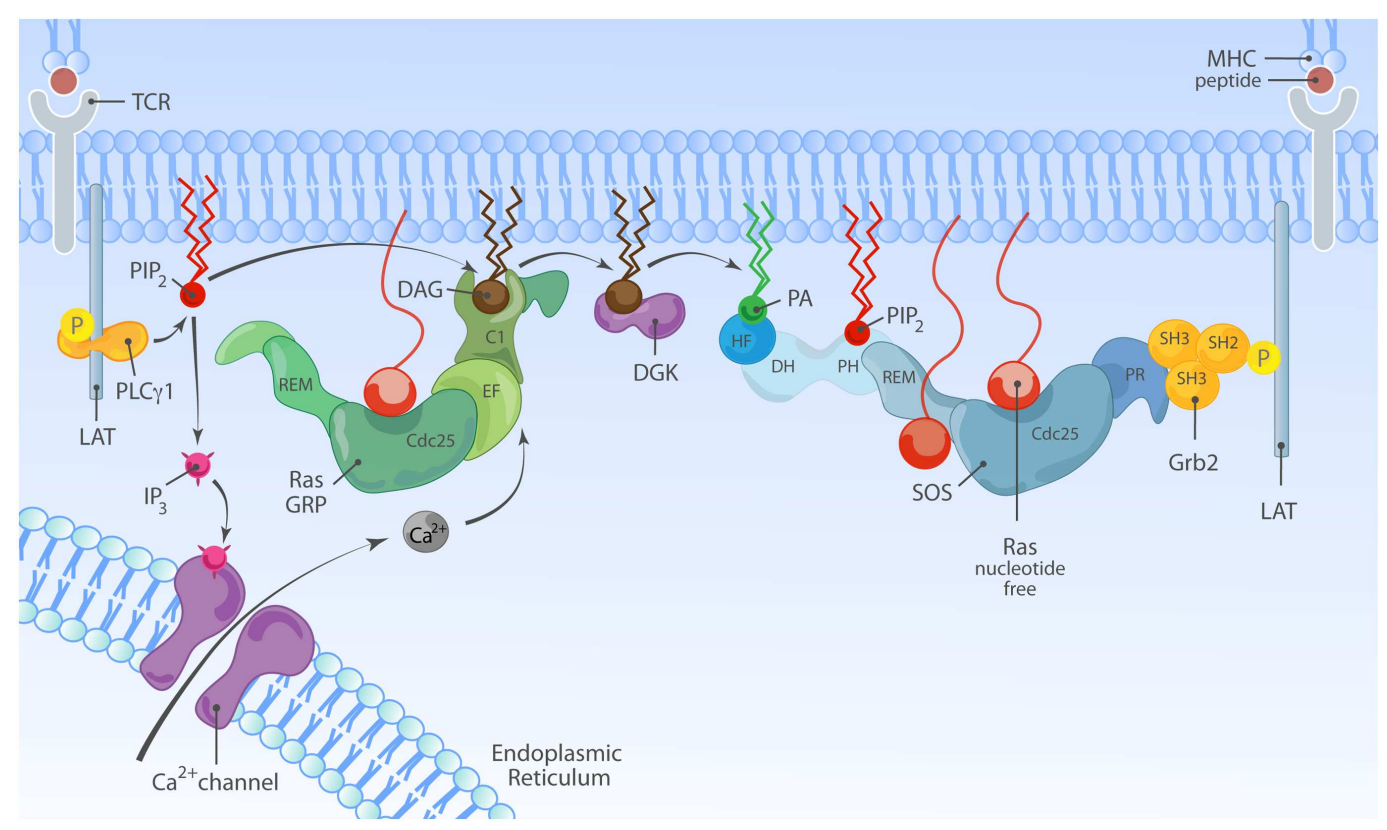

FIGURE 5 | Model of synergy between RasGRP and SOS in TCR signaling. TCR stimulation is connected to activation of RasGRP via tyrosine phosphorylation of the adapter molecule LAT and activation of PLC $\gamma 1$, that metabolizes $\mathrm{PIP}_{2}$ into $\mathrm{IP}_{3}$ and DAG to trigger two second messenger pathways; $\mathrm{Ca}^{2+}$ and DAG. Activated RasGRP can enhance the full activation of SOS by providing Ras.GTP, allosterically activating SOS. In principle, the TCR-LAT-PLC $\gamma 1$ pathway can also indirectly facilitate SOS activation via DAG; DGK metabolizes DAG and converts it to $\mathrm{PA}$, which is a possible target for the $\mathrm{HF}$ and/or $\mathrm{PH}$ domains in SOS. exclusive. Non-antigen receptor triggered pathways that are typically not associated with DAG production have been implicated in RasGRP1 membrane localization. Specifically, RasGRP1 but not RasGRP3 signals downstream of the CXCR4 chemokine receptor in thymocytes (123) and a heterodimer of TCR/CXCR4 has been described to recruit the PLC enzymes essential in this pathway (124). How different receptor systems couple to DAG and RasGRP and may be able to synergistically trigger this pathway is an interesting concept for future research.

Whereas RasGRP1 is expressed in various cell lineages $(20,46$, $61,62)$, it is most abundant in developing thymocytes, which perhaps offers an explanation for the fairly specific thymocyte developmental defect that is observed in RasGRP1-deficient animals (18). Reciprocally, RasGRP3 abundance is high in B lymphocytes and RasGRP3 deficient mice demonstrate B cell defects (99), although there is a role for RasGRP1 in this lineage as well, at least in early B cell subsets $(101,125)$. The developmental defects in thymocytes lacking RasGRP1 are a consequence of severely impaired positive selection of these cells and biochemically visible through the impaired activation of the ERK kinases (61). A causative link between the impaired RasGRP1-Ras-ERK signaling and defective positive selection has been very nicely provided through the analyses of ERK-1 and ERK-2 doubly deficient mice in which the thymocytes also show a positive selection defect (126). Perhaps surprisingly, other RasGEFs, be it of the RasGRP-, Rasgrf-, or SOS-type, do not effectively compensate for the loss of RasGRP1 in thymocytes. The fact that there is only minimal compensation for loss of RasGRP1 coming from RasGRP3 or RasGRP4 $(123,127)$ makes one wonder about the underlying mechanism.
Is it purely the relative abundance of RasGRP1 that bestows its unique function in thymocytes and would expression of RasGRP3 from the RasGRP1 promoter be able to compensate for the loss of RasGRP1? Or, are there unique biochemical properties in the RasGRP1 protein that are lacking in other RasGEFs?

\section{ADDITIONAL MECHANISMS OF RasGRP1 REGULATION}

Only a small portion of protein flanks RasGRP1's catalytic REMCdc25 core on the N-terminal side (Figure 2). There is no predicted protein domain in this N-terminal part, but this stretch is either only 9 or 57 amino acids long, depending on the use of an alternative internal start codon in RasGRP1 or its most N-terminal ATG codon (128). The C-terminus appears far more interesting. Not only does it contain the DAG-binding C1 domain, there are also a pair of EF hands sandwiched between the Cdc25 and C1 domains and a roughly 200-amino acid long C-terminal tail without clear domains except for a leucine zipper motif (51, 129, 130). Significantly, genetic deletion of this 200 -amino acid long C-terminal tail reduces the formation of mature thymocytes in RasGRP $1^{d / d}$ mice (131), thus there are critical regulatory functions encoded on RasGRP1's C-terminus that are relevant for thymocyte function.

Not all EF hands bind calcium, but RasGRP1 has been reported to bind calcium in vitro (51) and the position of the pair of $\mathrm{EF}$ hands between the catalytic core and the membrane-recruitment $\mathrm{C} 1$ unit is an interesting one. EF hands usually come in pairs and are structures consisting of two $\alpha$-helices connected by a loop that contain residues such as aspartic acid, which are critical for binding and positioning of a calcium ion. The calcium-binding event 
induces protein conformational changes through the alteration of the directional vectors of the $\alpha$-helices (50). It is very possible that calcium binding alters the structural conformation of RasGRP1 and other RasGRP family members. Deducting from cell biological assays, it appears that calcium orchestrates membrane recruitment of RasGRP together with DAG although this may vary from cell to cell type.

Kay and colleagues reported that in a chicken DT40 B cell line, the first EF hand pair enables the recruitment function of a Cterminal PT domain (PM targeting domain), which contains the leucine zipper motif (132). Mutation of the characteristic triplet of negatively charged aspartic acids in the first EF hand results in impaired enrichment of this RasGRP1-EF1 $\mu$ molecule to the PM, following either BCR or G-protein coupled receptor stimuli. Whereas both of RasGRP1's EF hands contain very similar triplets of aspartic acids, mutation of these into serine in the second EF hand does not impact the membrane recruitment of the RasGRP1-EF2 $\mu$ molecule (132). Intriguingly, the contribution of the PT domain toward membrane recruitment appears to differ from cell to cell type; it is substantial in BCR-stimulated B cell lines, very modest in $\mathrm{T}$ cell lines, and negligible in fibroblasts (129). It should also be noted that these studies relied on ectopic expression of RasGRP1 that was N-terminally tagged with GFP and that the $\mathrm{T}$ and $\mathrm{B}$ cells tested in this manner also express endogenous RasGRP1. We will discuss the relevance of overexpression of molecules in the Ras signaling pathway later. The concern of co-expressing a tagged (and mutated) RasGRP1 together with endogenous RasGRP1 is appropriate in light of the predicted leucine zipper. It is possible that the C-terminal leucine zipper motif functions as a RasGRP1 dimerization interface, which would make analysis of the individual contribution of introduced- versus endogenousRasGRP1 molecules complex. Regardless, the Kay group studies clearly revealed for the first time that calcium-dependent regulation, while incompletely understood, plays an important role in RasGRP1 signaling (Figure 4C). Consistent with the notion of calcium-dependent RasGRP1 regulation, the calcium chelator BAPTA-AM and a calcium channel blocker prevented the appearance of Ras.GTP at the Golgi of activated T-cells in imaging experiments (133) (see below for spatial considerations of Ras activation). In biochemical studies, removal of all free calcium by chelators had only a modest effect on TCR-driven Ras activation (134) and RasGRP1 can activate Ras in T-cells in the absence of free calcium (19), although it is difficult to asses the efficiency of calcium chelation or to determine how much cellular calcium would be needed to couple to RasGRP1. In addition, there is an enrichment of calcium ions near the negatively charged polar headgroups of phospholipids in the PM (135), the localization to which RasGRP1 is recruited via DAG. Perhaps it is the membrane-localized calcium that is most relevant to enhance RasGRP1 function. With these biochemical and cellular experiments in mind, it is interesting to speculate on how the regulation of various of the Lupus-associated RasGRP1 mRNA splice variants that lack portions of the EF hands may be altered (104).

Are there additional mechanisms of RasGRP membrane recruitment or retention that may rely on protein-protein interactions or phospholipids other than DAG? RasGRP1 can interact with a kinase dead version of PKC $\theta$ in transfected cells (100).

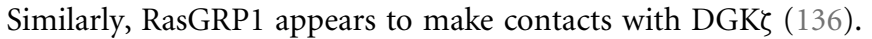
It is not clear at this point if these results reflect the common intersection point of DAG or if these are true (perhaps transient) protein-protein interactions between RasGRP1 and PKC $\theta$ or DGK $\zeta$ and what the biological implications of these may be for lymphocytes. SKAPP-55 is a multi-domain adapter molecule that interacts with RasGRP1 in a resting $\mathrm{T}$ cell line and SKAPP55/RasGRP1 interactions become more abundant upon TCR or integrin stimulation (137). The immunological implication of SKAPP55 function and its interaction with RasGRP1 are unclear, both a positive role (138) and a negative role (137) have been proposed. Besides a C-terminal SH3 domain, SKAP-55 contains an N-terminal PH domain (just like SOS). It is highly speculative but interesting to consider that both SOS and RasGRP1 may be regulated by phospholipids like $\mathrm{PIP}_{2}$ and $\mathrm{PA}$ interacting with $\mathrm{PH}$ domains, but that this occurs in an indirect manner for RasGRP1 through its interaction with SKAP-55. Lastly, Cornell and colleagues demonstrated that RasGRP1's PT domain harbors a basic/hydrophobic cluster of amino acids that is conserved among species and that a protein-purified PT domain can bind to phosphoinositide-containing vesicles (130). Thus, it appears that there will be multiple mechanisms of RasGRP activation and regulation, some perhaps surprisingly similar as for SOS RasGEFs.

\section{BIOCHEMICAL SYNERGY BETWEEN SOS1 AND RasGRP1}

When SOS and RasGRP's are co-expressed in a T cell, TCR stimulation can take two routes to Ras-ERK activation; one through RasGRP and the other through SOS (Figure 5). However, genetic studies in cell lines and mice indicate that RasGRP plays a more dominant role in antigen receptor-stimulated Ras-ERK activation $(18,61,66,67,92,139)$. A recent study also reports that SOS1/2 maybe inhibitory for TCR-induced ERK activation in human peripheral T cells (140), although this finding is inconsistent with several other studies showing a positive contribution of SOS in antigen receptor-stimulated ERK activation, both in lymphocyte cell lines and primary mouse and human lymphocytes (20, 65-67, 92). Reduction of SOS expression leads to moderate but consistent ERK activation impairment in human peripheral T cells, mouse DP thymocytes, and DT40 B cell line $(20,66,67,92,139)$. Furthermore, the ERK activation defect in $\mathrm{SOS}^{-}{ }^{-} 2^{-}$DT40 cells is most noticeable at low and physiological levels of antigen receptor stimulation, indicating that ranges of stimuli across multiple time points are required to conclusively analyze ERK activation defects $(66,92,139)$.

Interestingly, flow cytometry-based examination of ERK activation for single cells within a population revealed that not only the quantity but also quality of phosphorylated ERK (pERK) output differs depending on RasGEFs connecting stimulated antigen receptor to Ras (66). In the DT40 model B-cell system, the pERK pattern in BCR-stimulated wild-type DT40 cells (co-expressing RasGRP1/3 and SOS1/2) demonstrates a highly thresholded and bimodal/digital pERK pattern. RasGRP1/3 double-deficiency in DT40 cells results in poor pERK response consistent with near abolished ERK activation in RasGRP1-deficient mouse lymphocytes, indicating that RasGRP play a dominant role in ERK regulation (66). In the absence of SOS1/2, RasGRP1/3 can still activate ERK downstream of BCR, albeit at reduced level. More 
significantly, these flow-based assays show that RasGRP1/3-driven ERK activation gradually increases over time and displays analog/unimodal pERK patterns, but does not yield a bimodal pattern (Figure 6).

Multiple models at different levels of Ras/MAPK signal transduction explain the shaping of digital/bimodal ERK activation, such as Ras nano-clusters (141), dual negative feedback control by SHP-1 (142) or scaffold-mediated signal quality change (143), and subcellular location of cascade activity (144). But, none of pre-existing models explain the change in ERK activation pattern depending on the RasGEFs availability. Based on computer modeling analysis, we hypothesized that the optimal Ras-ERK response observed in wild-type cells co-expressing SOS and RasGRP involved allosteric activation of SOS primed by Ras.GTP produced by RasGRP. To test this hypothesis, we uncoupled the potential positive feedback loop between two RasGEFs by introducing W729E mutation that prevents Ras.GTP binding at the SOS1 allosteric pocket $(66,89,92)$. Whereas RasGRP1 is comparably activated (measured by T184 phosphorylation), BCR-induced Ras-ERK response in cells expressing W729E mutant-SOS1 resembles that of SOS1/2-deficient cells [unpublished data (92)]. Which RasGEF generates an initial flux of Ras.GTP priming full activation of SOS? Theoretically, allosteric activating Ras.GTP can come from self (SOS) or from RasGRP. Indeed, HeLa cervix carcinoma cells that do not express RasGRP1 (Roose lab, data not shown) are able to engage the SOS-Ras.GTP-SOS loop in response to EGFR stimulation (91). However, both lymphocyte cell lines and primary lymphocytes lacking RasGRP poorly respond in terms of Ras-ERK activation, indicating that RasGRP plays an essential role in ERK activation by signaling to Ras-ERK but also to Ras-SOS, via an early surge of Ras.GTP allosterically activating SOS (18, 61, 65-67, 92, 139).

\section{NOVEL INSIGHTS AND PUZZLES FOR THYMOCYTE SELECTION SIGNALS FROM MOUSE MODELS DEFICIENT FOR RasGEFs}

In the cellular context where two RasGEFs co-exist, biochemical activation of RasGRP appears temporally ahead of activation of SOS (Roose lab, data not shown). Moreover, whereas SOS requires allosteric activation by Ras.GTP and therefore in a sense relies on RasGRP1 (65), the reverse relationship does not exist: RasGRP1 does not appear to require SOS. These relationships between RasGRP/SOS lead to the hypothesis that the differential fate of thymocytes undergoing selection might be determined by how two RasGEFs are differentially activated upon TCR stimulation (145). This hypothesis was also founded by the observation that positively selected DP thymocytes demonstrate graded (or analog) ERK activation $(146,147)$. In this model, weak TCR stimulation of positively selected thymocytes sub-optimally phosphorylates LAT, enough to activate PLC $\gamma 1$-DAG-RasGRP1 pathway and analog ERK signals but without coupling SOS1 membrane recruitment and digital ERK signaling (Figure 6). Genetic support for this

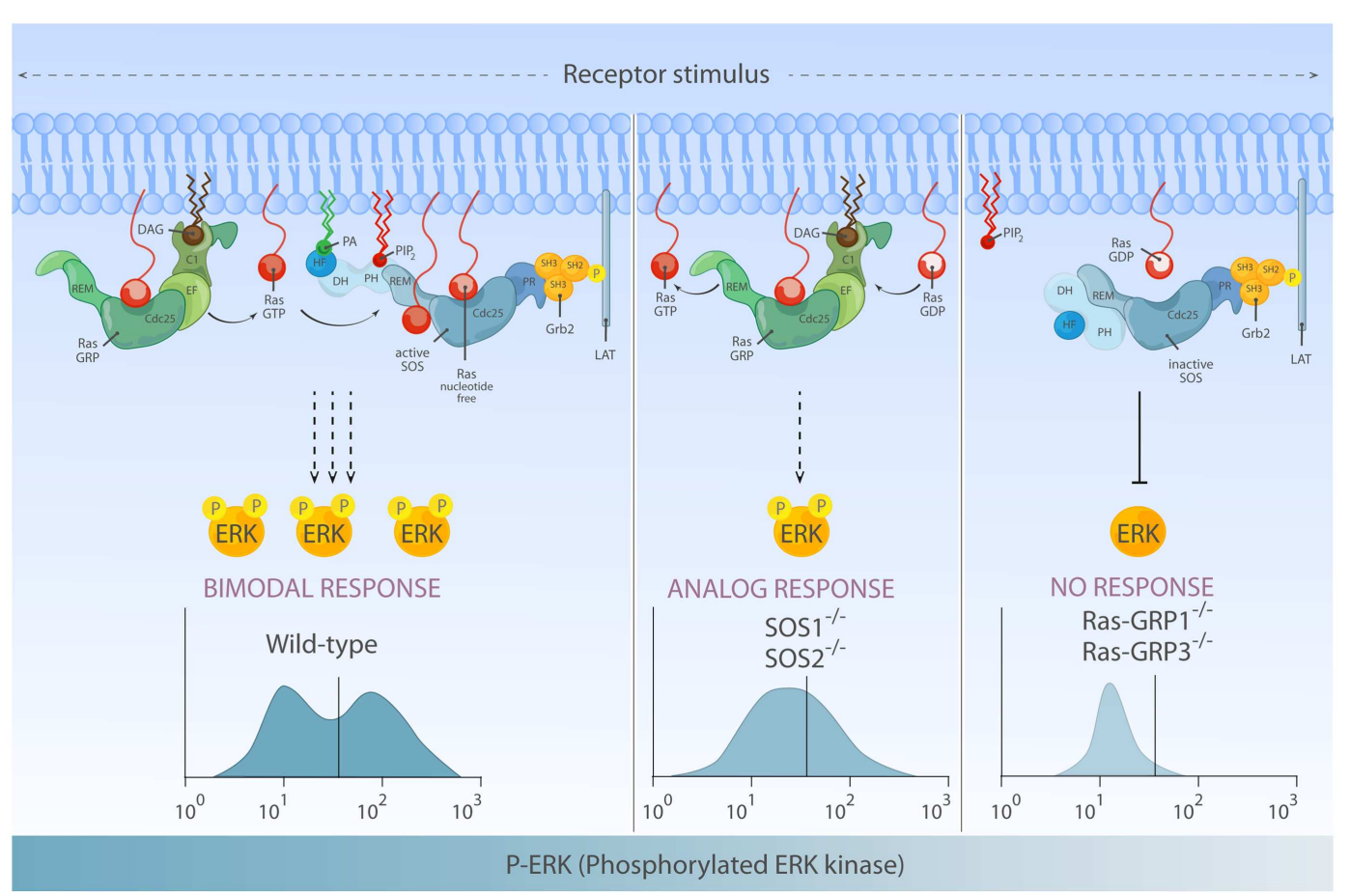

FIGURE 6 | Differential activation of RasGEF determines the quantity and quality of Ras-ERK output. Left: full activation of the ERK response requires activation of both RasGRP and SOS and can lead to bimodal (digital) ERK activation patterns. In this mode of signaling, RasGRP activation temporally precedes activation of SOS and provides initial Ras.GTP that primes full activation of SOS. Middle: in the absence of SOS, there is substantial
Ras-ERK activation mediated by RasGRP alone, but the ERK activation patterns are analog and therefore differs both quantitatively and qualitatively from ERK signal generated by two RasGEFs in synergy. Right: in lymphocytes, RasGRP plays a dominant role in connecting TCR-Ras-ERK pathway. SOS alone has difficulty to prime its own allosteric activation, which results in a high threshold for Ras-ERK activation. 
model comes from the observation that RasGRP1 is essential for positive selection but is not required for negative selection $(61,67)$. On the other hand, strong TCR stimulation during negative selection induces extensive LAT phosphorylation, enough to recruit and activate both RasGRP1 and SOS1, and enable allosteric activation of SOS, which generates strong ERK activation characteristic of negatively selected DP thymocytes $(66,147)$. Whereas this is a plausible model it does not address the question if digital SOS-ERK signals are negative selection cues for thymocytes. In fact, genetic deletion of $E R K-1$ and $E R K-2$ does not impair negative selection of DP thymocytes at all (148), perhaps arguing that the characteristic ERK activation profiles of thymocytes under negative selection conditions is only a byproduct of a different signal that causes the true negative selection (we will discuss this later). Furthermore, recent studies of a conditional SOS1 knockout mouse model from Samelson and colleagues provided yet another puzzling insight into the different roles of RasGEFs during T cell development (20, 67), which we will discuss next.

Conditional genetic deletion of SOS1 in thymocytes, $\operatorname{SOS} 1(\mathrm{~T})^{-1-}$ revealed that SOS1 is dispensable for negative selection, disfavoring the previously mentioned differential-RasGEFusage model for thymocyte fate decision [reviewed in Ref. (149)]. Instead, SOS1 expression is required for DN stage thymocytes undergoing DN to DP transition. SOS2 deficiency alone does not significantly affect either positive or negative selection (67). The developmental block in SOS1(T) ${ }^{-1-}$ thymocytes is accounted for by impaired proliferative expansion of DN to DP thymocytes (20). The early developmental defect in SOS1(T) ${ }^{-1-}$ thymocytes can be explained by developmental stage-specific expression profile of different RasGEFs: protein level of SOS1 and RasGRP1 dynamically changes as thymocytes develop. SOS1 protein level is highest in DN thymocytes, while DP thymocytes only express $20 \%$ of the SOS1 levels seen in DN thymocytes. RasGRP1 protein level follows the opposite trend: little RasGRP1 is expressed in DN, RasGRP1 is most abundant in DP thymocytes (20,61). Most puzzling is the finding that combined deletion of RasGRP1/SOS1 impairs negative selection (67). What would be the signaling components regulated by two RasGEFs for negative selection? It is unlikely to be Ras-ERK since negative selection is not affected in $\mathrm{H}-\mathrm{Ras}^{\mathrm{S} 17 \mathrm{~N}}$ transgenic nor in Erk $1^{-}$Erk2 ${ }^{-}$doubly deficient thymocytes, indicating that Ras-ERK activation is dispensable for negative selection $(12,148)$.

One explanation could be that rather than mediating TCRsparked responses, both GEFs provide a permissive type of input by sustaining steady-state, basal Ras and Ras-effector levels, as documented in other systems $(150,151)$. Another explanation may be provided by other functions of RasGEFs in addition to activation of the canonical Ras-ERK pathway. Pharmacological inhibition of the p38 MAPK impairs negative selection in fetal thymic organ culture system (152). Additionally, both Grb2 haploinsufficiency as well as complete Grb2 deletion is concomitant with reduced p38 activation and impaired negative selection $(153,154)$. We recently uncovered an unanticipated link between SOS and p38 (92). Significantly, SOS1 plays a critical role to connect TCR triggering to $\mathrm{p} 38$ activation. By contrast, RasGRP1 plays only a very minor regulatory role in TCR-induced $\mathrm{p} 38$ activation in human peripheral T cells and Jurkat cell line and p38 activation is unaffected in thymocytes deficient of RasGRP1 (92). Surprisingly, SOS1's role in p38 activation is independent of allosteric activation of SOS or even of any enzymatic activity in SOS1, arguing that this is indeed a non-canonical SOS pathway [discussed in more detail later; (92)].

\section{SPATIAL CONTROL OF Ras ACTIVATION: A ROLE FOR LIPID MESSENGERS AND GEFs IN COMPARTMENTALIZED Ras SIGNALING?}

Traditionally, Ras activation in leukocytes and other cell types has been intuitively assumed to proceed at the PM based on the notion that Ras activation is bound to happen in close proximity to growth factor or antigen receptor systems that do, in their majority, operate at the cell surface. Early immunocytochemical studies confirmed the predominant presence of Ras at the PM (155-162), lending support to the view that Ras activation proceeds at the PM. However, a diffuse staining of the cytoplasm was apparent in some reports $(155,161,163)$, suggesting early on that meaningful amounts of Ras proteins might also be present and signal from internal membranes (endomembranes). The concept that Ras proteins do associate with subcellular membranes was cemented in a series of studies from the 1980s documenting that Ras proteins are subject to a complex series of post-translational modifications that gradually increase their hydrophobicity and effectively govern the association of Ras with cellular membranes [for a review, see $(13,164,165)]$. Recent imaging studies have added a spatial and temporal dimension to this view by showing, firstly, that the stepwise post-translational processing of nascent Ras proteins proceeds at endomembranes en route to the PM (163), and second, by disclosing dynamic cycling of the two palmitoylated Ras proteins $\mathrm{H}$-Ras and N-Ras between PM and endomembranes in dependency of their palmitoylation status (166-169). According to this latter "acylation cycle" model, palmitoylation at the Golgi apparatus "traps" H-Ras and $\mathrm{N}$-Ras proteins at endomembranes, tagging them for exocytotic transport and accumulation at the PM. Upon depalmitoylation by the recently characterized acyl protein thioesterase 1 (APT1) $(167,170)$ and possibly other as yet unidentified depalmitoylating activities, Ras proteins loose their tight and inert binding to the PM, leading to a fast inter-membrane exchange of depalmitoylated Ras and, in consequence, to the tendency to distribute equally to all cellular membrane compartments. One round of the cycle is completed by the renewed palmitoylation of Ras at the Golgi apparatus, a reaction that essentially provides a vectorial component ensuring the predominant localization of Ras at the PM. In contrast to the dynamic palmitoylation-dependent cycling of $\mathrm{H}$-Ras and $\mathrm{N}$-Ras, the non-palmitoylated $\mathrm{K}$-Ras protein is assumed to reside and function largely at the PM, although alternative modes for K-Ras internalization have also been described $(171,172)$. Knowing this, the intriguing question is whether compartmentalization of Ras activity represents a means of signal diversification in antigen receptor signaling and whether or not second messenger lipids coordinate spatial aspects of Ras activation.

\section{IMAGING ACTIVE Ras.GTP IN T-CELLS}

In 2003, Mark Philips and coworkers presented the first of a series of studies that reported for the first time a view of Ras activation 
in real-time in lymphocytes challenged via the T-cell receptor $(133,173,174)$. Ras.GTP visualization was accomplished using a genetically encoded, fluorescent reporter probe composed of EGFP and the Ras-binding domain (RBD) of the Ras-effector c-Raf. EGFP-RBD features several orders of magnitude higher affinity for Ras.GTP versus Ras.GDP causing it to redistribute and illuminate subcellular sites of Ras.GTP accumulation (162, 175, 176). However, levels of endogenous Ras.GTP are too low to be visualized by EGFP-RBD and researchers have been forced to overexpress Ras. Use of EGFP-RBD to image activation of overexpressed Ras in Jurkat T-cells challenged by clustering the CD $3 \varepsilon$ chain of the TCR alone or in combination with co-stimulatory triggers yielded an unexpected picture: a bimodal pattern of Ras activation consisting of K-Ras activation at the PM followed or paralleled by a more sustained accumulation of N-Ras.GTP at the Golgi apparatus (173). Strikingly, N-Ras became GTP-loaded only at the Golgi despite the fact that it was present in large amounts at the PM, where the same TCR stimulation induced robust GTP loading of K-Ras (174). While the precise mechanisms enabling the TCR to discriminate among Ras isoforms and subcellular platforms of activation are not fully clear, a number of factors involved in spatial control of Ras activation have been characterized. Pharmacological experiments and use of genetically engineered Jurkat lines provided evidence that the delayed Golgi activation of N-Ras occurred by means of a PLC $\gamma 1 /$ RasGRP1 pathway acting specifically on Golgi-resident N-Ras $(133,173)$, whereas SOS and RasGRP1 acted in concert to load K-Ras with GTP at the PM. Intriguingly, the segregation of the Ras.GTP reporter probe to PM versus endomembranes depended on a number of stimulation parameters: first, the strength of TCR stimulation, with low-grade stimulation (achieved by applying CD3 and CD28 cross-linking antibodies at a final concentration of $1 \mu \mathrm{g} / \mathrm{ml}$ ) causing the accumulation of the Ras.GTP reporter only at the Golgi apparatus, whilst high-grade stimulation $(5 \mu \mathrm{g} / \mathrm{ml})$ lead to the described $\mathrm{b}$ dual activation pattern $(133,173)$. This distinct activation pattern was attributed to the ability of lowgrade TCR signals to engage the Golgi-specific PLC $\gamma 1 /$ RasGRP1 pathway but not other pathways targeting K-Ras at the PM (173). Arguing against this scenario, other investigators have reported $\mathrm{K}$-Ras activation in response to anti CD $3 \varepsilon$ Abs administered at concentrations as low as $0.15 \mu \mathrm{g} / \mathrm{ml}(19,177)$, suggesting that low-grade TCR signals cannot discriminate between PM and endomembrane Ras-pools or between K-Ras and N-Ras isoforms. Interestingly, non-leukocyte cell lines like COS, MDCK, or HeLa, which do not express RasGRP1 $(150,168)$ (Roose, unpublished) exhibit the same segregation of EGFP-RBD to the PM and Golgi in response to growth factor stimulation $(133,169,178,179)$, evidencing that mechanisms of endomembrane Ras activation other than the RasGRP pathway do exist. Data from Bastiaens lab illustrate that (overexpressed) Ras.GTP generated at the PM of MDCK cells relocates to endomembranes following its depalmitoylation at the cell surface in the context of the acylation cycle $(169,179)$. This mode of endomembrane Ras activation may well operate also in $\mathrm{T}$ lymphocytes, but this would imply that endomembrane Ras activation should be preceded by a first "wave" of $\mathrm{N}$-Ras activation at the PM, which was not reported in those studies $(173,174)$. In conclusion, the individual contribution of the two known modes of endomembrane Ras activation in TCR signaling in $\mathrm{T}$ lymphocytes still needs to be evaluated in detail.

\section{THE ROLE OF CO-STIMULATION}

Another parameter that can affect the spatial segregation of Ras.GTP is the nature of the co-stimulus provided along with the CD3-cross-linking Ab. For example, CD28 co-stimulation enhances DAG production in T-cells $(121,180)$ and this in turn is expected to enhance Ras activation via RasGRP1. CD28 costimulation is thus intuitively expected to affect the magnitude and possibly also the location of Ras-GTP formation. Somewhat unexpectedly, therefore, this turned out not to be the case, since co-stimulation with soluble CD28 antibodies does not ostensibly affect Ras.GTP levels and/or Ras.GTP localization $(174,177)$. Perhaps CD3/CD28 co-stimulation experiments need to be reevaluated using immobilized rather than soluble Abs for receptor crosslinking (181). Co-stimulation via the lymphocyte functionassociated antigen-1 (LFA-1), on the other hand, was reported to stimulate activation of Ras at the PM (174). Interestingly, LFA-1 facilitated Ras.GTP formation by stimulating the generation of DAG at the PM via the sequential action of PLD2 and Phosphatidic acid phosphate (PAP), a pathway that had before been linked to DAG/PA metabolism at the Golgi (182). In agreement with an important role of LFA-1 signals for Ras.GTP formation, co-stimulation via LFA-1 reportedly enhanced Ras-GTP accumulation in response to TCR-clustering (174). In opposition to that scenario, others have not observed an effect of LFA-1 on Ras-GTP levels in T-cells (177). Along the same vein, co-stimulating T-cells via SLAM, a measure that also leads to an enhanced production of DAG in T cells (180) did not further stimulate Ras.GTP production, further indicating that an elevation of DAG levels in response to particular TCR/co-receptor stimulations does not always automatically translate in elevated Ras.GTP levels.

\section{ENDOGENOUS VERSUS OVEREXPRESSED Ras AND OTHER EXPERIMENTAL CONSIDERATIONS}

The pioneering imaging studies described above have changed the way we think about Ras activation, away from the traditional, rather unilateral view of "static" Ras proteins acting at the PM to the more dynamic picture that has now emerged and has been delineated in the previous sections. It is, however, important to recall that the experimental approaches that have led to this new conception feature a number of caveats and limitations that should be borne in mind. One limitation is that stimulation with cross-linking antibodies toward the $\mathrm{CD} 3 \varepsilon$ chain and various co-receptors, as used for reasons of simplicity in most studies, may not reliably reflect the physiological setting of a T-cell challenged by an antigen-loaded APC. Secondly, overexpression of Ras proteins, as applied in most imaging experiments, is an issue worth considering.

Since Ras activation and trafficking are finely regulated processes it is arduous to judge whether or not images obtained from cells overexpressing Ras proteins do always truly reflect the behavior of endogenous Ras. Evidence arguing that this may indeed be an important fact to bear in mind comes from studies reporting on the subcellular localization of endogenous Ras·GTP 
in live T cells $(177,183)$. Visualization of endogenous levels of Ras.GTP in T cells was achieved using refined fluorescent biosensors for Ras.GTP that consisted of three concatenated RBD modules, yielding increased avidity toward Ras.GTP (183), and three EGFP proteins, that conferred threefold higher fluorescence intensity to the probes (177). These probes redistributed only to the PM of PMA or TCR-stimulated Jurkat cells and to the immunological synapse of primary $\mathrm{T}$ lymphocytes conjugated to APCs $(177,183)$, but the probes did not illuminate the Golgi or other endomembranes, in contrast to what was observed in T cells overexpressing H-Ras or N-Ras $(133,174)$. This remarkable variance in experimental outcome can be interpreted in two ways: first, the trivalent $\mathrm{EGFP} \times 3$ - $\mathrm{RBD} \times 3$ reporter probes do illuminate endogenous Ras.GTP formed at the PM but they are not sensitive enough to visualize Ras.GTP at the Golgi. Since the signals obtained for endogenous Ras. GTP at the PM using the EGFP $\times 3$ $\mathrm{RBD} \times 3$ biosensors are clear and well visible, this interpretation would imply that Ras.GTP levels at the Golgi are markedly lower than those at the PM. The alternative explanation is that accumulation of N-Ras.GTP at the Golgi results from perturbances in Ras trafficking, processing, or activation processes as a consequence of Ras overexpression. For example, the reported relocation of GAPs to the cell surface at later stages of TCR signaling for the shutdown of PM Ras signaling $(133,184)$ could cause a drop in GAP activity at endomembranes that could facilitate increased Ras.GTP loading at the Golgi in a background of Ras overexpression. Also, a sheer increase in the flux of N-Ras through the acylation cycle in Ras overexpressing T-cells is expected to lead to the redistribution of more N-Ras.GTP from the PM to endomembranes. In sum, it is currently difficult to judge whether the observed accumulation of overexpressed N-Ras.GTP at the Golgi is a physiological response of T-cells to antigen stimulation or rather reflects an effect that is only seen with anomalously high levels of Ras.

\section{COMPARTMENTALIZATION OF DAG-RasGRP1 SIGNALS}

Given that Ras activation downstream of the activated TCR is largely driven by the concerted action of SOS and RasGRP1 GEFs, can knowledge about the segregation of GEFs and the lipid second messengers that regulates GEF action help us understand the spatial control of Ras activation? The subcellular distribution and TCR-dependent, spatially localized formation of DAG, as the most prominent lipid second messenger involved in the regulation of Ras activity, have been investigated in quite some detail. In addition to its presence at the PM, DAG is present in meaningful amounts at various other subcellular sites including the Golgi apparatus and the nuclear membrane $(185,186)$. It appears that the sources for these distinct pools of DAG are different. For example, DAG at the Golgi arises largely from Sphingosine metabolism and to some extent also from the sequential action of PLD and PAP on phospholipids $(182,187)$. PM-located and nuclear DAG is mostly replenished by de novo synthesis but is also generated to a variable extent by the action of Phospholipases of various kinds on precursor phospholipids (for comprehensive reviews on DAG metabolism see $(187,188)$ and in this review issue). Although lymphocytes reportedly have a pool of nuclear DAG, too (186), most attention has been devoted to the PM and Golgi-populations of DAG, since these are, arguably, the two major platforms of TCR signaling. While some subcellular sites, prominently the Golgi apparatus, are rich in steady-state levels of DAG (182), it is generally assumed that DAG-dependent signaling downstream of the TCR involves the de novo generation and spatially restricted accumulation of DAG in response to antigen stimulation. Since DAG can directly recruit the Ras activator RasGRP1 it appears reasonable to predict, that domains of DAG formation in response to TCR stimulation should coincide with sites of Ras.GTP accumulation.

Where does TCR-sparked DAG production occur and where within the antigen-stimulated T-cell does DAG accumulate? Several laboratories have imaged DAG in live T-cells using fluorescent reporter probes derived from DAG-binding domains including C1 domains from RasGRP1, PKC $\theta$, or PKD (189-192). Interestingly, $\mathrm{C} 1$ domains from RasGRP1 or PKC $\theta$ illuminated endomembranes in unstimulated T-cells, suggesting that resting levels of DAG in Tcells are primarily found in that compartment. Upon conjugation with APCs, the same reporter probes relocalized to the IS (190, 191), illustrating that DAG accumulates at the IS. The accumulation of active PLC $\gamma 1$ (assessed by phosphorylation on Y783) to PM and IS in response to TCR cross-linking or conjugation with APCs (193) is also in line with this view. Consistent with the notion that TCR-activation induces DAG formation/accumulation at the PM, the full-length versions of the DAG-effector proteins PKD and chimaerins accumulate at the PM or IS of TCR-challenged T-cells (194). DGK $\alpha$ and DGK $\zeta$, two enzymes that metabolize DAG by converting it to PA, also accumulate at the PM of T-lymphocytes conjugated to antigen-loaded APCs $(192,195)$, a step proposed to be critical for the spatial confinement of DAG to the IS (196). In the case of RasGRP1, some studies reported exclusive redistribution of RasGRP1 to the PM or IS of T-cells challenged via the TCR $(122,177,194,197-200)$ while others documented TCRactivation dependent accumulation of RasGRP1 at PM and Golgi $(133,147,174)$. Importantly, while these considerations may cause the impression that DAG alone determines the subcellular distribution of many of its effector proteins, DAG is likely to be only one of various factors that coincidentally determine the spatial distribution of RasGRP1 and other DAG-target proteins. For example, the DAG-effector PKD features a transient and short-lived recruitment to the IS despite the much more prolonged presence of DAG at the IS (191).

\section{COMPARTMENTALIZATION OF LIPID-SOS SIGNALS?}

Recently, the lipid product of PLD, PA, has been reported to recruit SOS via its $\mathrm{PH}$ domain, thus providing yet a new link for a lipid messenger and Ras activation. Since PA is found both at the PM and endomembranes $(174,182)$, mechanisms for the oriented and regulated recruitment of SOS to subcellular membranes must exist. This involves probably the concerted action of PA with other upstream inputs such as $\mathrm{PIP}_{2}$, Ras-binding, and Grb2 binding, as described extensively above (see sections on SOS regulation).

Another important second messenger lipid with relevance to SOS-driven Ras activation is the $\mathrm{PI} 3 \mathrm{~K}$ reaction product phosphatidylinositol-3,4,5 trisphosphate $\left(\mathrm{PIP}_{3}\right)(201,202)$. The subcellular distribution of $\mathrm{PIP}_{3}$ in lymphocytes has been visualized using fluorescent reporter proteins based on the $\mathrm{PH}$-domain of Akt (203-205). These studies reported that $\mathrm{PIP}_{3}$ was produced and accumulated at the PM, but in contrast to DAG, $\mathrm{PIP}_{3}$ was 
not restricted to the IS but expanded also to regions outside the IS (203). Indeed, a sustained accumulation of $\mathrm{PIP}_{3}$ was even observed at the antisynapse or uropod of the T-cell (204). Remarkably, other upstream modulators or known activators of Ras like ZAP70 and ezrin, respectively, also accumulate at the antipodal pole of conjugated T-cells (206-208). Intriguingly, ezrin is an important co-factor in Sos activation in some systems (207), which raises the intriguing possibility that concerted Sos-dependent Ras activation by means of ezrin and $\mathrm{PIP}_{3}$ and subsequent Ras-signaling (to PI3K?) may proceed at the T-cell uropod at later stages of T-cell-APC conjugation.

The subcellular distribution of $\mathrm{PIP}_{3}$ in the course of T-cell stimulation is consistent and certainly suggestive of a role of PI3K in the control of Ras activation and/or signal propagation. However, the precise role played by PI3K and its lipid products in Ras activation is an intensively debated, and as yet not settled issue. PI3Ks [refers collectivelly to the four members of the class I family of PI3Ks (209)] were originally described and characterized as effector proteins of Ras, and a large body of experimental evidence [including the recent analysis of transgenic animals expressing PI3K variants that cannot be activated by Ras.GTP $(210,211)]$ has firmly established the notion that PI3Ks do function downstream of Ras [reviewed in Ref. (212)]. On the other hand, a number of studies has also documented a role for PI3K upstream of Ras (201, 202, 213), indicating that PI3K lipid products could fulfill dual roles as second messengers in the propagation of Ras-sparked signals and as modulators in the (feedback?) control of Ras activation.

How could PI3K lipid products regulate Ras activation in lymphocytes? $\mathrm{PIP}_{3}$ interacts physically with the Ras-GAP species GAP1(m) (214) and biochemical evidence for a regulation of RasGAP activities by $\mathrm{PIP}_{3}$ in leukocytes does exist (202). Beyond this largely unexplored connection with GAP proteins, $\mathrm{PIP}_{3}$ interacts with and recruits members of the Tec family of protein kinases, prominently Bruton's tyrosine kinase, Btk, in B cells and Itk in T-cells (215), via an amino-terminal PH domain (216-218). Tec kinases, in turn, can affect Ras activation in two ways: first, Tec kinases are critically involved in antigen receptor-induced PLC $\gamma$ activation $(219,220)$, and defective Tec activation in response to antigen receptor stimulation leads to a number of defects in pathways dependent on DAG/IP3, including PKC and ERK activation $(221,222)$. The latter finding suggests that Ras activation should also be affected, although this has, to our knowledge, not been directly assessed. Secondly, defects in Tec kinase function cause a decrease in PA levels (223), which could in turn result in diminished Ras.GTP loading via SOS (29). In this regard, it is probably important to consider $\mathrm{PIP}_{3}$ in a broader context in conjunction with the fate of its precursor lipid $\mathrm{PIP}_{2}$. Beyond serving as a substrate for PI3Ks, $\mathrm{PIP}_{2}$ plays a critical function as the substrate of PLC $\gamma$ enzymes and it is well established that the agonist-evoked activation of PI3K and PLC $\gamma$ signaling can lead to a marked, acute and probably spatially restricted drop of $\mathrm{PIP}_{2}$ levels in leukocytes (224, 225). Since $\mathrm{PIP}_{2}$ can modulate Ras activation via the direct, $\mathrm{PH}$-domain dependent interaction with SOS, the concerted and locally confined regulation of the $\mathrm{PIP}_{2} / \mathrm{PIP}_{3}$ ratio is predicted to have a large impact on the activation status of Ras. From a technical point of view, one important challenge for the years to come will be to address this aspect of Ras activation by visualizing $\mathrm{PIP}_{2}$ and
$\mathrm{PIP}_{3}$ simultaneously with Ras.GTP in life cells, an approach that should ideally be expanded to other second messengers involved in the control of RasGEFs.

\section{A PHYSIOLOGICAL ROLE FOR COMPARTMENTALIZED Ras SIGNALING?}

Is the segregation of Ras signaling to endomembranes and possibly other subcellular sites an inherent and fundamental component of TCR signaling that provides an additional level of signal diversification? Evidence for a possible physiological role of compartmentalized Ras signaling in T-cell biology comes from provocative data reported by Ed Palmer's lab arguing that Ras localization and signaling from PM versus endomembranes could be a major fate determinant during thymic T-cell selection (147). Using a collection of agonist ovalbumin (OVA) peptide variants with graded affinities toward the TCR on transgenic OT-I T lymphocytes these investigators observed a distinct compartmentalization of Ras and its downstream effector protein c-Raf (also known as Raf-1) in dependency of agonist strength: in T-cells driven into negative selection by high-affinity antigen peptides Ras and c-Raf distributed largely to the PM whilst positive selecting, low affinity ligands induced a relocation of Ras and Raf to endomembranes. Intriguingly, localization of RasGRP1 followed a similar pattern. At first sight the relocation of Ras signaling to endomembranes by highaffinity ligands in the thymocyte selection model and by low-grade TCR stimulation of Jurkat cells in the study by Perez de Castro et al. (173) may appear hard to reconcile, although it is probably tedious to compare peptide/APC-stimulation of immature double-positive thymocytes with Jurkat cells or primary mature $\mathrm{T}$ cells challenged by means of cross-linking Abs. It is also important to note that Ras accumulation at endomembranes, as observed in positively selected thymocytes, must not necessarily reflect high Ras.GTP loading and Ras signaling at that organelle. In this regard, the coincident accumulation of Raf in the Golgi apparatus of positively selected thymocytes may not be a reliable marker for the presence of Ras.GTP as suggested (147). Since only about 3\% of c-Raf interacts with Ras.GTP in antigen challenged T-cells at the peak of Ras.GTP formation (226), the observed quantitative relocation of c-Raf to endomembranes is unlikely to result from recruitment by Ras.GTP but could rather argue for the action of a small second messenger molecule in recruiting c-Raf. For example, c-Raf is recruited and activated by PA $(227,228)$, and thus PA generated by DGK-catalyzed phosphorylation of DAG or by PLD activation downstream of PKC $(229,230)$ is an attractive candidate in this respect. In sum, the documentation of spatial Ras segregation in the context of thymic selection provides important evidence for a role of compartmentalized Ras signaling in T-cell biology, but we need to understand more about the underlying mechanisms governing spatial control of Ras activity. Moreover, the fact that mice devoid of both palmitoylated Ras variants, $\mathrm{H}$-Ras and N-Ras, live a mostly healthy life (231), have normal T-cell differentiation and feature only relatively minor defects in mature lymphocyte biology (232) evidences that the compartmentalization of Ras signaling to endomembranes is not essential or critically important for TCR-dependent signaling, at least in rodents. Perhaps the ability to compartmentalize Ras signals to endomembranes is part of a signaling repertoire for fine-tuning 
of TCR responses, the physiological relevance of which has so far escaped our attention.

\section{SOS1 AS A LIPID REGULATED ADAPTER MOLECULE}

Overshadowed by its primary role as a RasGEF in the canonical SOS-Ras pathways, it is relatively underappreciated that SOS1 may function as a scaffold molecule that can potentially sense membrane lipid- and protein-originated signals. Particularly interesting is SOS's PR C-terminal segment with multiple potential SH3 binding sites (PxxP motifs) and at least four sites that bind to Grb2's SH3 domain in vitro $(32,233)$. The multiplicity of the SH3 ligand sites in the $\mathrm{C}$-terminus bestows the capacity to interact with more than one interacting partner at any one time. The availability for multiple PxxP motifs opens the possibility for interacting with more than one molecule of Grb2 or other related SOS-interacting $\mathrm{SH} 3-\mathrm{SH} 2-\mathrm{SH} 3$ adapters such as Grap or Gads. Thus, SOS may function as a scaffold to integrate upstream membrane signals and coordinate activation of multiple downstream pathways.

Houtman and colleagues actually observed complexes of SOS1 and Grb2 in a 1:2 stoichiometry, particularly when molar concentration of Grb2 is in excess (234). The multivalent interaction between Grb2 and SOS can lead to formation of oligomeric LAT clusters, in this case, SOS-Grb2 complex functions as a cytosolic adapter cross-linking multiple LAT molecules together (234236) (Figure 7). Expression of PR C-terminal SOS1 fragment in Jurkat cells decreases the size of aggregated LAT clusters and also attenuates weak TCR stimuli-induced calcium flux (234). These observations support the functional existence of SOS-Grb2-LAT clusters, which can facilitate amplification of weak TCR stimulation. SOS can also synergize with LAT clusters by stabilizing LAT signalosome components such as PLC $\gamma 1$. Upon TCR stimulation, PLC $\gamma 1-\mathrm{SH} 2$ is recruited and bound to tyrosine-phosphorylated (Y132; human or Y136; mouse) LAT $(237,238)$. In addition, the $\mathrm{SH} 3$ domain of PLC $\gamma 1$ directly interacts with PR segments of SOS both in vitro and in vivo, including in T lymphocytes (3538). Direct SOS-PLC $\gamma 1$ binding can promote stable association of PLC $\gamma 1$ within LAT signalosome by collaborating with SH2-PLC $\gamma 1$ binding with phospho-LAT. Additionally, direct SOS-PLC $\gamma 1$ interaction can recruit PLC $\gamma 1$ to the proximity of its substrate, $\mathrm{PIP}_{2}$, which is also a ligand for the HF and $\mathrm{PH}$ domains of SOS as described earlier. Thus, it is plausible that LAT and SOS together nucleate a signaling hub in lymphocytes in which many molecules and therefore pathways come together.

Our recent study indicates that SOS1 plays an important adapter function regulating p 38 pathway activation independently of SOS1' catalytic activity (92). In principle, SOS1's DH domain could act as nucleotide exchange domain in a SOS-Rac-P38 pathway since $\mathrm{DH}$ domains are commonly shared structural modules of GEFs regulating Rho family GTPases such as $\operatorname{Rac}(23,239)$. Indeed, SOS has been suggested to operate as a GEF with dual specificity: REM-Cdc25 domains targeting for Ras and $\mathrm{DH}$ and $\mathrm{PH}$ domain for Rac (240). The latter activity occurs in epithelial cells when SOS1 is coupled to EPS8 and E3b1 co-factors (22, 23, 39). Rac.GTP accumulation is thought to be upstream of classical p38 activation pathway $(241,242)$. Interestingly, the absence of SOS-1 and -2 profoundly impairs BCR-stimulated Rac.GTP accumulation and p38 activation (92). Combined deficiency of

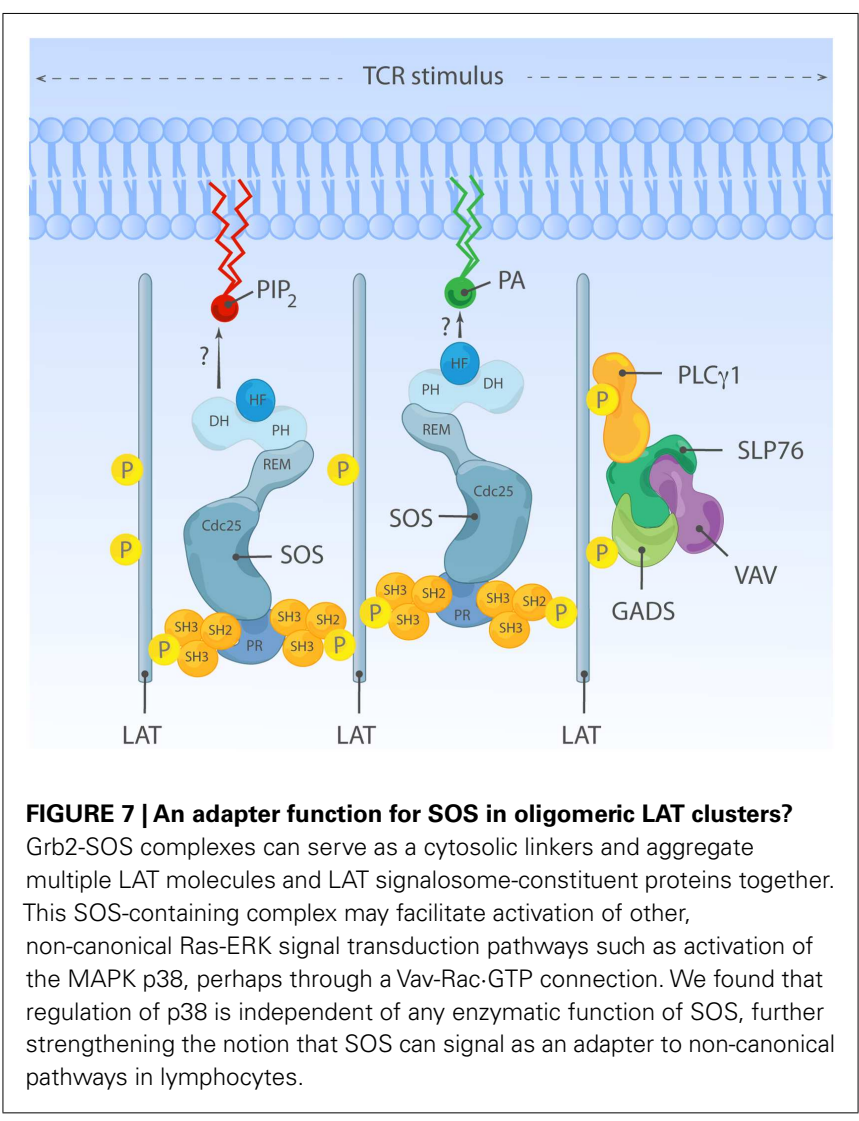

RasGRP-1 and -3 abolishes BCR-induced ERK activation, while its impact on $\mathrm{p} 38$ phosphorylation (pT180pY182) is only minimal (92). Unexpectedly, SOS1 versions with either a point mutation (F929A) within Cdc25 that cripples SOS1's RasGEF function, an allosteric pocket mutation W729E, or a mutation of seven amino acids in the DH domain (LHYFELL $\rightarrow$ IIIRDII) that would disrupt SOS1's putative RacGEF activity, all rescue BCR-induced p38 phosphorylation in SOS-deficient DT40 B cells, indicating that enzymatic activity of SOS1 is not required for p38 regulation and SOS1 is functioning as an adapter for p38 activation pathway (92). Thus, whereas the exact nature of SOS1's adapter function and the potential role of phospholipids binding to SOS1 as an adapter (Figure 7) remain to be further studied, p38 appears to connect to a non-canonical SOS pathway in lymphocytes.

\section{CONCLUDING REMARKS}

The need for controlled Ras activation in not only lymphocytes but also in all other cell types is clearly provided by the devastating consequences of aberrant, oncogenic Ras signals in cancer. Not all cell types express both the SOS and RasGRP types of RasGEFs and lymphocytes are perhaps somewhat unique in that these cells have developed an intricate mechanism for sensitive and robust Ras signals via both types of RasGEFs that is still under tight control. We have discussed how membrane recruitment and biochemical activation of the RasGRP and SOS RasGEF is fine-tuned through the concerted input of various mechanisms that include lipid messengers. Future research will undoubtedly further refine the model of Ras activation we sketched here and may reveal how 
lipid messengers could integrate signals to RasGRP and SOS as adapters in non-canonical pathways that are distinct from Ras.

\section{ACKNOWLEDGMENTS}

We thank Ion Cirstea for helpful suggestions and editing the review and Anna Hupalowska for generating the illustrations.

\section{REFERENCES}

1. Chang L, Karin M. Mammalian MAP kinase signalling cascades. Nature (2001) 410:37-40. doi:10. $1038 / 35068583$

2. Vetter IR, Wittinghofer A. The guanine nucleotide-binding switch in three dimensions. Science (2001) 294:1299-304. doi:10.1126/science.1062023

3. Rajalingam K, Schreck R, Rapp UR, Albert S. Ras oncogenes and their downstream targets. Biochim Biophys Acta (2007) 1773:1177-95. doi:10.1016/j.bbamcr.2007.01.012

4. Ahearn IM, Haigis K, Bar-Sagi D, Philips MR. Regulating the regulator: post-translational modification of RAS. Nat Rev Mol Cell Biol (2012) 13:39-51. doi:10.1038/ nrm3255

5. Bos JL, Rehmann H, Wittinghofer A. GEFs and GAPs: critical elements in the control of small G proteins. Cell (2007) 129:865-77. doi:10.1016/j.cell.2007.05.018

6. Bos JL. Ras oncogenes in human cancer: a review. Cancer Res (1989) 49:4682-9.

7. Karnoub AE, Weinberg RA. Ras oncogenes: split personalities. Nat Rev Mol Cell Biol (2008) 9:517-31. doi: $10.1038 / \mathrm{nrm} 2438$

8. Vigil D, Cherfils J, Rossman KL, Der CJ. Ras superfamily GEFs and GAPs: validated and tractable targets for cancer therapy? Nat Rev Cancer (2010) 10:842-57. doi:10. $1038 / \mathrm{nrc} 2960$

9. Downward J, Graves JD, Warne PH, Rayter S, Cantrell DA. Stimulation of p21ras upon T-cell activation. Nature (1990) 346:719-23. doi: $10.1038 / 346719 \mathrm{a} 0$

10. Graves JD, Downward J, IzquierdoPastor M, Rayter S, Warne PH, Cantrell DA. The growth factor IL-2 activates p21ras proteins in normal human T lymphocytes. $J$ Immunol (1992) 148:2417-22.

11. Alberola-Ila J, Forbush KA, Seger R, Krebs EG, Perlmutter RM. Selective requirement for MAP kinase activation in thymocyte differentiation. Nature (1995) 373:620-3. doi:10.1038/373620a0

12. Swan KA, Alberola-Ila J, Gross JA, Appleby MW, Forbush KA, Thomas JF, et al. Involvement of p21ras distinguishes positive and negative selection in thymocytes. EMBO J (1995) 14:276-85.

13. Mor A, Philips MR. Compartmentalized Ras/MAPK signaling. Annu Rev Immunol (2006) 24:771-800. doi:10.1146/annurev.immunol.24. 021605.090723

14. Yasuda T, Kurosaki T. Regulation of lymphocyte fate by Ras/ERK signals. Cell Cycle (2008) 7:3634-40 doi:10.4161/cc.7.23.7103

15. Stone JC. Regulation and function of the RasGRP family of Ras activators in blood cells. Genes Cancer (2011) 2:320-34. doi:10.1177/ 1947601911408082

16. John J, Rensland H, Schlichting I, Vetter I, Borasio GD, Goody RS, et al. Kinetic and structural analysis of the $\mathrm{Mg}(2+)$-binding site of the guanine nucleotide-binding protein p21H-ras. J Biol Chem (1993) 268:923-9.

17. Cool RH, Schmidt G, Lenzen CU, Prinz H, Vogt D, Wittinghofer A. The Ras mutant D119N is both dominant negative and activated. Mol Cell Biol (1999) 19:6297-305.

18. Dower NA, Stang SL, Bottorff DA, Ebinu JO, Dickie P, Ostergaard HL, et al. RasGRP is essential for mouse thymocyte differentiation and TCR signaling. Nat Immunol (2000) 1:317-21. doi:10. 1038/80799

19. Ebinu JO, Stang SL, Teixeira C, Bottorff DA, Hooton J, Blumberg PM, et al. RasGRP links T-cell receptor signaling to Ras. Blood (2000) 95:3199-203.

20. Kortum RL, Sommers CL, Alexander CP, Pinski JM, Li W, Grinberg A, et al. Targeted Sos1 deletion reveals its critical role in early T-cell development. Proc Natl Acad Sci U S A (2011) 108:12407-12. doi:10.1073/pnas.1104295108

21. Sondermann H, Soisson SM, BarSagi D, Kuriyan J. Tandem histone folds in the structure of the $\mathrm{N}$ terminal segment of the ras activator Son of Sevenless. Structure (2003) 11:1583-93. doi:10.1016/j. str.2003.10.015

22. Nimnual AS, Yatsula BA, BarSagi D. Coupling of Ras and Rac guanosine triphosphatases through the Ras exchanger Sos. Science (1998) 279:560-3. doi:10. $1126 /$ science. 279.5350 .560

Our research is supported by a Sandler Program in Basic Science (start-up Jeroen P. Roose), Physical Science Oncology Center grant U54CA143874 (Jeroen P. Roose), NIH grant 1P01AI091580-01 (Jesse E. Jun, Jeroen P. Roose), DFG grant RU 860/4-1 (Ignacio Rubio), and DFG GRK1715 (Ignacio Rubio).

23. Soisson SM, Nimnual AS, Uy M, Bar-Sagi D, Kuriyan J. Crystal structure of the Dbl and pleckstrin homology domains from the human Son of sevenless protein. Cell (1998) 95:259-68. doi:10. 1016/S0092-8674(00)81756-0

24. Lemmon MA. Membrane recognition by phospholipid-binding domains. Nat Rev Mol Cell Biol (2008) 9:99-111. doi:10.1038/ nrm 2328

25. Chen RH, Corbalan-Garcia S, BarSagi D. The role of the $\mathrm{PH}$ domain in the signal-dependent membrane targeting of Sos. EMBO J (1997) 16:1351-9. doi:10.1093/ emboj/16.6.1351

26. Koshiba S, Kigawa T, Kim JH, Shirouzu M, Bowtell D, Yokoyama S. The solution structure of the pleckstrin homology domain of mouse Son-of-sevenless 1 (mSos 1$)$. J Mol Biol (1997) 269:579-91. doi:10.1006/jmbi.1997.1041

27. Kubiseski TJ, Chook YM, Parris WE, Rozakis-Adcock M, Pawson T. High affinity binding of the pleckstrin homology domain of mSos1 to phosphatidylinositol (4,5)-bisphosphate. J Biol Chem (1997) 272:1799-804. doi: 10.1074/jbc.272.3.1799

28. Zheng J, Chen RH, Corblan-Garcia S, Cahill SM, Bar-Sagi D, Cowburn D. The solution structure of the pleckstrin homology domain of human SOS1. A possible structural role for the sequential association of diffuse B cell lymphoma and pleckstrin homology domains. J Biol Chem (1997) 272:30340-4. doi:10.1074/jbc.272.48.30340

29. Zhao C, Du G, Skowronek K, Frohman MA, Bar-Sagi D. Phospholipase D2-generated phosphatidic acid couples EGFR stimulation to Ras activation by Sos. Nat Cell Biol (2007) 9:706-12. doi:10. 1038/ncb1594

30. Boriack-Sjodin PA, Margarit SM, Bar-Sagi D, Kuriyan J. The structural basis of the activation of Ras by Sos. Nature (1998) 394:337-43. doi:10.1038/28548

31. Margarit SM, Sondermann $H$, Hall BE, Nagar B, Hoelz A, Pirruccello M, et al. Structural evidence for feedback activation by Ras.GTP of the Ras-specific nucleotide exchange factor SOS. Cell (2003) 112:685-95. doi:10. 1016/S0092-8674(03)00149-1

32. Egan SE, Giddings BW, Brooks MW, Buday L, Sizeland AM, Weinberg RA. Association of Sos Ras exchange protein with Grb2 is implicated in tyrosine kinase signa transduction and transformation. Nature (1993) 363:45-51. doi:10. 1038/363045a0

33. Li N, Batzer A, Daly R, Yajnik V, Skolnik E, Chardin P, et al. Guanine-nucleotide-releasing factor hSos1 binds to Grb2 and links receptor tyrosine kinases to Ras signalling. Nature (1993) 363:858. doi:10.1038/363085a0

34. Innocenti M, Frittoli E, Ponzanelli I, Falck JR, Brachmann SM, Di Fiore PP, et al. Phosphoinositide 3-kinase activates Rac by entering in a complex with Eps8, Abil, and Sos-1. J Cell Biol (2003) 160:17-23. doi:10.1083/jcb 200206079

35. Kim MJ, Chang JS, Park SK, Hwang JI, Ryu SH, Suh PG. Direct interaction of SOS1 Ras exchange protein with the SH3 domain of phospholipase C-gamma1. Biochemistry (2000) 39:8674-82. doi:10. 1021/bi992558t

36. Scholler JK, Perez-Villar JJ, O’Day K, Kanner SB. Engagement of the $\mathrm{T}$ lymphocyte antigen receptor regulates association of son-ofsevenless homologues with the $\mathrm{SH} 3$ domain of phospholipase Cgamma1. Eur J Immunol (2000) 30:2378-87. doi:10.1002/15214141(2000)30:8<2378::AIDIMMU2378>3.0.CO;2-E

37. Halupa A, Chohan M, Stickle NH, Beattie BK, Miller BA, Barber DL. Erythropoietin receptor Y479 couples to ERK1/2 activation via recruitment of phospholipase Cgamma. Exp Cell Res (2005) 309:1-11. doi:10.1016/j. yexcr.2005.04.030

38. Wu C, Ma MH, Brown KR, Geisler M, Li L, Tzeng E, et al. Systematic identification of $\mathrm{SH} 3$ domain-mediated human proteinprotein interactions by peptide array target screening. Proteomics (2007) 7:1775-85. doi:10.1002/ pmic. 200601006 
39. Innocenti M, Tenca P, Frittoli E, Faretta M, Tocchetti A, Di Fiore $\mathrm{PP}$, et al. Mechanisms through which Sos-1 coordinates the activation of Ras and Rac. J Cell Biol (2002) 156:125-36. doi:10.1083/ jcb. 200108035

40. Rozakis-Adcock M, Van Der Geer P, Mbamalu G, Pawson T. MAP kinase phosphorylation of mSos 1 promotes dissociation of mSos1Shc and mSos1-EGF receptor complexes. Oncogene (1995) 11:141726.

41. Waters SB, Holt KH, Ross SE, Syu LJ, Guan KL, Saltiel AR, et al. Desensitization of Ras activation by a feedback disassociation of the SOS-Grb2 complex. J Biol Chem (1995) 270:20883-6. doi:10.1074/ jbc. 270.36 .20883

42. Corbalan-Garcia S, Degenhardt KR, Bar-Sagi D. Insulin-induced dissociation of Sos from Grb2 does not contribute to the down regulation of Ras activation. Oncogene (1996) 12:1063-8.

43. Corbalan-Garcia S, Yang SS, Degenhardt KR, Bar-Sagi D. Identification of the mitogen-activated protein kinase phosphorylation sites on human Sos1 that regulate interaction with Grb2. Mol Cell Biol (1996) 16:5674-82.

44. Porfiri E, McCormick F. Regulation of epidermal growth factor receptor signaling by phosphorylation of the ras exchange factor hSOS1. J Biol Chem (1996) 271:5871-7. doi:10.1074/jbc.271. 10.5871

45. Clyde-Smith J, Silins G, Gartside M, Grimmond S, Etheridge M, Apolloni A, et al. Characterization of RasGRP2, a plasma membrane-targeted, dual specificity Ras/Rap exchange factor. $J$ Biol Chem (2000) 275:32260-7. doi:10.1074/jbc.M006087200

46. Kawasaki H, Springett GM, Toki S, Canales JJ, Harlan P, Blumenstiel JP, et al. A Rap guanine nucleotide exchange factor enriched highly in the basal ganglia. Proc Natl Acad Sci U S A (1998) 95:13278-83. doi:10.1073/pnas.95.22.13278

47. Irie K, Masuda A, Shindo M, Nakagawa Y, Ohigashi H. Tumor promoter binding of the protein kinase $\mathrm{C} \mathrm{C1}$ homology domain peptides of RasGRPs, chimaerins, and Unc13s. Bioorg Med Chem (2004) 12:4575-83. doi:10.1016/j. bmc.2004.07.008

48. Johnson JE, Goulding RE, Ding Z, Partovi A, Anthony KV, Beaulieu $\mathrm{N}$, et al. Differential membrane binding and diacylglycerol recognition by $\mathrm{C} 1$ domains of RasGRPs. Biochem J (2007) 406:22336. doi:10.1042/BJ20070294

49. Grabarek Z. Structural basis for diversity of the EF-hand calciumbinding proteins. $J \mathrm{Mol} \mathrm{Biol}$ (2006) 359:509-25. doi:10.1016/j. jmb.2006.03.066

50. Gifford JL, Walsh MP, Vogel HJ. Structures and metal-ion-binding properties of the $\mathrm{Ca} 2+$-binding helix-loop-helix EF-hand motifs. Biochem I (2007) 405:199-221. doi:10.1042/BJ20070255

51. Ebinu JO, Bottorff DA, Chan EY, Stang SL, Dunn RJ, Stone JC. RasGRP, a Ras guanyl nucleotide-releasing protein with calcium- and diacylglycerolbinding motifs. Science (1998) 280:1082-6. doi:10.1126/science. 280.5366.1082

52. Ksionda O, Limnander A, Roose JP. RasGRP proteins in cancer. Front Biol (2013) (in press).

53. Fernandez-Medarde A, Santos E. The RasGrf family of mammalian guanine nucleotide exchange factors. Biochim Biophys Acta (2011) 1815:170-88. doi:10.1016/j.bbcan. 2010.11.001

54. Cen H, Papageorge AG, Vass WC, Zhang KE, Lowy DR. Regulated and constitutive activity by CDC25Mm (GRF), a Ras-specific exchange factor. Mol Cell Biol (1993) 13:7718-24.

55. Lemmon MA, Ferguson KM. Signal-dependent membrane targeting by pleckstrin homology (PH) domains. Biochem J (2000) 350(Pt 1):1-18. doi:10.1042/02646021:3500001

56. Parry DA, Fraser RD, Squire JM. Fifty years of coiled-coils and alpha-helical bundles: a close relationship between sequence and structure. J Struct Biol (2008) 163:258-69. doi:10.1016/j.jsb.2008.01.016

57. Bahler M, Rhoads A. Calmodulin signaling via the IQ motif. FEBS Lett (2002) 513:107-13. doi:10. 1016/S0014-5793(01)03239-2

58. Buchsbaum RJ, Connolly BA, Feig LA. Interaction of Rac exchange factors Tiam1 and Ras-GRF1 with a scaffold for the p38 mitogenactivated protein kinase cascade. Mol Cell Biol (2002) 22:407385. doi:10.1128/MCB.22.12.40734085.2002

59. Fan WT, Koch CA, De Hoog CL, Fam NP, Moran MF. The exchange factor Ras-GRF2 activates Rasdependent and Rac-dependent mitogen-activated protein kinase pathways. Curr Biol (1998)
8:935-8. doi:10.1016/S09609822(07)00376-4

60. Kiyono M, Satoh T, Kaziro Y. G protein beta gamma subunit-dependent Rac-guanine nucleotide exchange activity of Ras-GRF1/CDC25(Mm). Proc Natl Acad Sci U $S \quad A \quad$ (1999) 96:4826-31. doi:10.1073/pnas.96.9.4826

61. Priatel JJ, Teh SJ, Dower NA, Stone JC, Teh HS. RasGRP1 transduces low-grade TCR signals which are critical for $\mathrm{T}$ cell development, homeostasis, and differentiation. Immunity (2002) 17:617-27. doi: 10.1016/S1074-7613(02)00451-X

62. Rambaratsingh RA, Stone JC, Blumberg PM, Lorenzo PS. RasGRP1 represents a novel nonprotein kinase $\mathrm{C}$ phorbol ester signaling pathway in mouse epidermal keratinocytes. J Biol Chem (2003) 278:52792-801. doi:10. 1074/jbc.M308240200

63. Zippel R, Gnesutta N, MatusLeibovitch N, Mancinelli E, Saya D, Vogel Z, et al. Ras-GRF, the activator of Ras, is expressed preferentially in mature neurons of the central nervous system. Brain Res Mol Brain Res (1997) 48:140-4. doi:10.1016/S0169328X(97)00120-4

64. Ruiz S, Santos E, Bustelo XR. RasGRF2, a guanosine nucleotide exchange factor for Ras GTPases, participates in T-cell signaling responses. Mol Cell Biol (2007) 27:8127-42. doi:10.1128/MCB.00912-07

65. Roose JP, Mollenauer M, Ho M, Kurosaki T, Weiss A. Unusual interplay of two types of Ras activators, RasGRP and SOS, establishes sensitive and robust Ras activation in lymphocytes. Mol Cell Biol (2007) 27:2732-45. doi:10.1128/ MCB.01882-06

66. Das J, Ho M, Zikherman J, Govern C, Yang M, Weiss A, et al. Digital signaling and hysteresis characterize ras activation in lymphoid cells. Cell (2009) 136:337-51. doi: 10.1016/j.cell.2008.11.051

67. Kortum RL, Sommers CL, Pinski JM, Alexander CP, Merrill RK, Li $\mathrm{W}$, et al. Deconstructing Ras signaling in the thymus. Mol Cell Biol (2012) 32:2748-59. doi:10.1128/ MCB.00317-12

68. Schubbert S, Shannon K, Bollag G. Hyperactive Ras in developmental disorders and cancer. Nat Rev Cancer (2007) 7:295-308. doi:10.1038/ nrc2 175

69. Roberts AE, Allanson JE, Tartaglia M, Gelb BD. Noonan syndrome.
Lancet (2013) 381:333-42. doi:10. 1016/S0140-6736(12)61023-X

70. Roberts AE, Araki T, Swanson $\mathrm{KD}$, Montgomery KT, Schiripo TA, Joshi VA, et al. Germline gainof-function mutations in SOS1 cause Noonan syndrome. Nat Genet (2007) 39:70-4. doi:10. 1038/ng1926

71. Tartaglia M, Pennacchio LA, Zhao C, Yadav KK, Fodale V, Sarkozy A, et al. Gain-of-function SOS1 mutations cause a distinctive form of Noonan syndrome. Nat Genet (2007) 39:75-9. doi:10. 1038/ng0207-276a

72. Zenker M, Horn D, Wieczorek D, Allanson J, Pauli S, Van Der Burgt I, et al. SOS1 is the second most common Noonan gene but plays no major role in cardio-faciocutaneous syndrome. J Med Genet (2007) 44:651-6. doi:10.1136/jmg. 2007.051276

73. Lepri F, De Luca A, Stella L, Rossi C, Baldassarre G, Pantaleoni $\mathrm{F}$, et al. SOS1 mutations in Noonan syndrome: molecular spectrum, structural insights on pathogenic effects, and genotype-phenotype correlations. Hum Mutat (2011) 32:760-72. doi:10.1002/humu.21492

74. Chen PC, Wakimoto H, Conner D, Araki T, Yuan T, Roberts A, et al. Activation of multiple signaling pathways causes developmental defects in mice with a Noonan syndrome-associated Sos1 mutation. J Clin Invest (2010) 120:4353-65. doi:10.1172/ JCI43910

75. Yadav KK, Bar-Sagi D. Allosteric gating of Son of sevenless activity by the histone domain. Proc Natl Acad Sci U S A (2010) 107:343640. doi:10.1073/pnas.0914315107

76. Oliveira JB, Bidere N, Niemela JE, Zheng L, Sakai K, Nix CP, et al. NRAS mutation causes a human autoimmune lymphoproliferative syndrome. Proc Natl Acad Sci U S A (2007) 104:8953-8. doi:10.1073/ pnas.0702975104

77. Niemela JE, Lu L, Fleisher TA, Davis J, Caminha I, Natter M, et al. Somatic KRAS mutations associated with a human nonmalignant syndrome of autoimmunity and abnormal leukocyte homeostasis. Blood (2011) 117:2883-6. doi:10. 1182/blood-2010-07-295501

78. Shannon K, Li Q. Oncogenic Ras scales the ALPS. Blood (2011) 117:2747-8. doi:10.1182/blood2010-12-320721

79. Takagi M, Shinoda K, Piao J, Mitsuiki $N$, Takagi M, Matsuda $\mathrm{K}$, et 
al. Autoimmune lymphoproliferative syndrome-like disease with somatic KRAS mutation. Blood (2011) 117:2887-90. doi:10.1182/ blood-2010-08-301515

80. Kane LP, Lin J, Weiss A. Signal transduction by the TCR for antigen. Curr Opin Immunol (2000) 12:242-9. doi:10.1016/ S0952-7915(00)00083-2

81. Buday L, Downward J. Epidermal growth factor regulates p21ras through the formation of a complex of receptor, Grb2 adapter protein, and Sos nucleotide exchange factor. Cell (1993) 73:611-20. doi:10.1016/00928674(93)90146-H

82. Buday L, Egan SE, Rodriguez Viciana P, Cantrell DA, Downward J. A complex of Grb2 adaptor protein, Sos exchange factor, and a 36-kDa membrane-bound tyrosine phosphoprotein is implicated in ras activation in T cells. $J$ Biol Chem (1994) 269:9019-23.

83. Aronheim A, Engelberg D, Li $\mathrm{N}$, Al-Alawi N, Schlessinger J, Karin M. Membrane targeting of the nucleotide exchange factor Sos is sufficient for activating the Ras signaling pathway. Cell (1994) 78:949-61. doi:10. 1016/0092-8674(94)90271-2

84. McCollam L, Bonfini L, Karlovich CA, Conway BR, Kozma LM, Banerjee U, et al. Functional roles for the pleckstrin and Dbl homology regions in the Ras exchange factor Son-of-sevenless. $J$ Biol Chem (1995) 270:15954-7. doi:10. 1074/jbc.270.27.15954

85. Wang W, Fisher EM, Jia Q, Dunn JM, Porfiri E, Downward J, et al. The Grb2 binding domain of mSos1 is not required for downstream signal transduction. Nat Genet (1995) 10:294-300. doi:10. 1038/ng0795-294

86. Corbalan-Garcia S, Margarit SM, Galron D, Yang SS, Bar-Sagi D. Regulation of Sos activity by intramolecular interactions. Mol Cell Biol (1998) 18:880-6.

87. Findlay GM, Smith MJ, Lanner F, Hsiung MS, Gish GD, Petsalaki E, et al. Interaction domains of sos1/grb2 are finely tuned for cooperative control of embryonic stem cell fate. Cell (2013) 152:1008-20. doi:10.1016/ j.cell.2013.01.056

88. Gureasko J, Kuchment O, Makino DL, Sondermann H, Bar-Sagi D, Kuriyan J. Role of the histone domain in the autoinhibition and activation of the Ras activator Son of Sevenless. Proc Natl Acad Sci U S
A (2010) 107:3430-5. doi:10.1073/ pnas.0913915107

89. Sondermann H, Soisson SM, Boykevisch S, Yang SS, Bar-Sagi D, Kuriyan J. Structural analysis of autoinhibition in the Ras activator Son of sevenless. Cell (2004) 119:393-405. doi:10.1016/ j.cell.2004.10.005

90. Freedman TS, Sondermann H, Friedland GD, Kortemme T, BarSagi D, Marqusee S, et al. A Rasinduced conformational switch in the Ras activator Son of sevenless. Proc Natl Acad Sci U S A (2006) 103:16692-7. doi:10.1073/ pnas.0608127103

91. Boykevisch S, Zhao C, Sondermann H, Philippidou P, Halegoua S, Kuriyan J, et al. Regulation of ras signaling dynamics by Sos-mediated positive feedback. Curr Biol (2006) 16:2173-9. doi: 10.1016/j.cub.2006.09.033

92. Jun JE, Li M, Chen H, Chakraborty AK, Roose JP. Activation of ERK but not of p38 MAP kinase pathways in lymphocytes requires allosteric activation of SOS. Mol Cell Biol (2013) 33:2470-84. doi: 10.1128/MCB.01593-12

93. Gureasko J, Galush WJ, Boykevisch S, Sondermann $\mathrm{H}$, Bar-Sagi D, Groves JT, et al. Membrane-dependent signal integration by the Ras activator Son of sevenless. Nat Struct Mol Biol (2008) 15:452-61. doi:10.1038/nsmb.1418

94. Sondermann H, Nagar B, Bar-Sagi D, Kuriyan J. Computational docking and solution $\mathrm{x}$-ray scattering predict a membrane-interacting role for the histone domain of the Ras activator son of sevenless. Proc Natl Acad Sci U S A (2005) 102:16632-7. doi:10.1073/ pnas.0508315102

95. Krishna S, Zhong X-P. Regulation of lipid signaling by diacylglycerol kinases during $\mathrm{T}$ cell development and function. Front Immunol (2013) 4:178. doi:10.3389/fimmu. 2013.00178

96. Sauer K, Cooke, MP. Regulation of immune cell development through soluble inositol1,3,4,5-tetrakisphosphate. Nat Rev Immunol (2010) 10:257-71. doi: 10.1038/nri2745

97. Aiba Y, Oh-Hora M, Kiyonaka S, Kimura Y, Hijikata A, Mori Y, et al. Activation of RasGRP3 by phosphorylation of Thr-133 is required for B cell receptor-mediated Ras activation. Proc Natl Acad Sci US A (2004) 101:16612-7. doi:10.1073/ pnas.0407468101
98. Brodie C, Steinhart R, Kazimirsky G, Rubinfeld H, Hyman T, Ayres $\mathrm{JN}$, et al. PKCdelta associates with and is involved in the phosphorylation of RasGRP3 in response to phorbol esters. Mol Pharmacol (2004) 66:76-84. doi:10.1124/mol. 66.1 .76

99. Coughlin JJ, Stang SL, Dower NA, Stone JC. RasGRP1 and RasGRP3 regulate $B$ cell proliferation by facilitating B cell receptor-Ras signaling. J Immunol (2005) 175:7179-84.

100. Roose JP, Mollenauer M, Gupta VA, Stone J, Weiss A. A diacylglycerolprotein kinase C-RasGRP1 pathway directs Ras activation upon antigen receptor stimulation of $\mathrm{T}$ cells. Mol Cell Biol (2005) 25:442641. doi:10.1128/MCB.25.11.44264441.2005

101. Limnander A, Depeille P, Freedman TS, Liou J, Leitges $M$, Kurosaki T, et al. STIM1, PKCdelta and RasGRP set a threshold for proapoptotic Erk signaling during B cell development. Nat Immunol (2011) 12:425-33. doi: 10.1038/ni.2016

102. Qu HQ, Grant SF, Bradfield JP, Kim C, Frackelton E, Hakonarson $\mathrm{H}$, et al. Association of RASGRP1 with type 1 diabetes is revealed by combined follow-up of two genome-wide studies. J Med Genet (2009) 46:553-4. doi:10.1136/jmg. 2009.067140

103. Plagnol V, Howson JM, Smyth DJ, Walker N, Hafler JP, Wallace $\mathrm{C}$, et al. Genome-wide association analysis of autoantibody positivity in type 1 diabetes cases. PLoS Genet (2011) 7:e1002216. doi:10. 1371/journal.pgen.1002216

104. Yasuda S, Stevens RL, Terada $\mathrm{T}$, Takeda M, Hashimoto $\mathrm{T}$, Fukae J, et al. Defective expression of Ras guanyl nucleotidereleasing protein 1 in a subset of patients with systemic lupus erythematosus. J Immunol (2007) 179:4890-900.

105. Reuther GW, Lambert QT, Rebhun JF, Caligiuri MA, Quilliam LA, Der CJ. RasGRP4 is a novel Ras activator isolated from acute myeloid leukemia. J Biol Chem (2002) 277:30508-14. doi: 10.1074/jbc.M111330200

106. Yang D, Tao J, Li L, Kedei $\mathrm{N}$, Toth ZE, Czap A, et al. RasGRP3, a Ras activator, contributes to signaling and the tumorigenic phenotype in human melanoma. Oncogene (2011) 30: 4590-600. doi:10.1038/onc.2011. 166
107. Yang D, Kedei N, Li L, Tao J, Velasquez JF, Michalowski AM, et al. RasGRP3 contributes to formation and maintenance of the prostate cancer phenotype. Cancer Res (2010) 70:7905-17. doi:10. 1158/0008-5472.CAN-09-4729

108. Luke CT, Oki-Idouchi CE, Cline JM, Lorenzo PS. RasGRP1 overexpression in the epidermis of transgenic mice contributes to tumor progression during multistage skin carcinogenesis. Cancer Res (2007) 67:10190-7. doi:10.1158/0008-5472.CAN-072375

109. Oki-Idouchi CE, Lorenzo PS Transgenic overexpression of RasGRP1 in mouse epidermis results in spontaneous tumors of the skin. Cancer Res (2007) 67:27680. doi:10.1158/0008-5472.CAN06-3080

110. Diez FR, Garrido AA, Sharma A, Luke CT, Stone JC, Dower NA, et al. RasGRP1 transgenic mice develop cutaneous squamous cell carcinomas in response to skin wounding. Potential role of granulocyte colony-stimulating factor. Am J Pathol (2009) 175:392-9. doi: 10.2353/ajpath.2009.090036

111. Klinger MB, Guilbault B, Goulding RE, Kay RJ. Deregulated expression of RasGRP1 initiates thymic lymphomagenesis independently of Tcell receptors. Oncogene (2005) 24:2695-704. doi:10.1038/si.onc. 1208334

112. Mikkers H, Allen J, Knipscheer P, Romeijn L, Hart A, Vink E, et al. High-throughput retroviral tagging to identify components of specific signaling pathways in cancer. Nat Genet (2002) 32:153-9. doi:10.1038/ng1002-331d

113. Suzuki T, Shen H, Akagi K, Morse HC, Malley JD, Naiman DQ, et al. New genes involved in cancer identified by retroviral tagging. Nat Genet (2002) 32:166-74. doi: 10.1038/ng1002-331e

114. Akagi K, Suzuki T, Stephens RM, Jenkins NA, Copeland NG. RTCGD: retroviral tagged cancer gene database. Nucleic Acids Res (2004) 32:D523-7. doi:10.1093/ nar/gkh013

115. Oki T, Kitaura J, Watanabe-Okochi $\mathrm{N}$, Nishimura K, Maehara A, Uchida T, et al. Aberrant expression of RasGRP1 cooperates with gain-of-function NOTCH1 mutations in T-cell leukemogenesis. Leukemia (2012) 26:1038-45. doi: 10.1038/leu.2011.328

116. Hartzell C, Ksionda O, Lemmens E, Coakley K, Yang M, Dail M, et al. 
Dysregulated RasGRP1 responds to cytokine receptor input in $\mathrm{T}$ cell leukemogenesis. Sci Signal (2013) 6:ra21. doi:10.1126/ scisignal.2003848

117. Feske S. Calcium signalling in lymphocyte activation and disease. Nat Rev Immunol (2007) 7:690-702. doi:10.1038/nri2152

118. Zheng Y, Liu H, Coughlin J, Zheng J, Li L, Stone JC. Phosphorylation of RasGRP3 on threonine 133 provides a mechanistic link between PKC and RAS signaling systems in B cells. Blood (2005) 105:3648-54. doi:10.1182/blood-2004-10-3916

119. Fu G, Chen Y, Yu M, Podd A, Schuman J, He Y, et al. Phospholipase $\mathrm{C}\{$ gamma $\} 1$ is essential for $\mathrm{T}$ cell development, activation, and tolerance. J Exp Med (2010) 207:309-18. doi:10.1084/ jem.20090880

120. Guo R, Wan CK, Carpenter JH, Mousallem T, Boustany RM, Kuan CT, et al. Synergistic control of T cell development and tumor suppression by diacylglycerol kinase alpha and zeta. Proc Natl Acad Sci U S A (2008) 105:11909-14. doi: 10.1073/pnas.0711856105

121. Olenchock BA, Guo R, Carpenter JH, Jordan M, Topham MK, Koretzky GA, et al. Disruption of diacylglycerol metabolism impairs the induction of T cell anergy. Nat Immunol (2006) 7:1174-81. doi: 10.1038/ni1400

122. Zha Y, Marks R, Ho AW, Peterson AC, Janardhan S, Brown I, et al. $\mathrm{T}$ cell anergy is reversed by active Ras and is regulated by diacylglycerol kinase-alpha. Nat Immunol (2006) 7:1166-73. doi: 10.1038/ni1206-1343a

123. Golec DP, Dower NA, Stone JC, Baldwin TA. RasGRP1, but not RasGRP3, is required for efficient thymic beta-selection and ERK activation downstream of CXCR4. PLoS One (2013) 8:e53300. doi:10. 1371/journal.pone. 0053300

124. Kremer KN, Clift IC, Miamen AG, Bamidele AO, Qian NX, Humphreys TD, et al. Stromal cellderived factor-1 signaling via the CXCR4-TCR heterodimer requires phospholipase C-beta3 and phospholipase C-gammal for distinct cellular responses. J Immunol (2011) 187:1440-7. doi:10.4049/ jimmunol.1100820

125. Limnander A, Weiss A. Cadependent Ras/Erk signaling mediates negative selection of autoreactive B cells. Small GTPases (2011) 2:282-8. doi:10.4161/sgtp.2.5.17794
126. Fischer AM, Katayama CD, Pages G, Pouyssegur J, Hedrick SM. The role of erk1 and erk2 in multiple stages of $\mathrm{T}$ cell development. Immunity (2005) 23:431-43. doi: 10.1016/j.immuni.2005.08.013

127. Zhu M, Fuller DM, Zhang W. The role of Ras guanine nucleotide releasing protein 4 in Fc epsilonRImediated signaling, mast cell function, and T cell development. J Biol Chem (2012) 287:8135-43. doi:10. 1074/jbc.M111.320580

128. Poon HY, Stone JC. Functional links between diacylglycerol and phosphatidylinositol signaling systems in human leukocyte-derived cell lines. Biochem Biophys Res Commun (2009) 390:1395-401. doi:10.1016/j.bbrc.2009.11.004

129. Beaulieu N, Zahedi B, Goulding RE, Tazmini G, Anthony $\mathrm{KV}$, Omeis SL, et al. Regulation of RasGRP1 by B cell antigen receptor requires cooperativity between three domains controlling translocation to the plasma membrane. Mol Biol Cell (2007) 18:3156-68. doi:10.1091/mbc. E06-10-0932

130. Zahedi B, Goo HJ, Beaulieu N, Tazmini G, Kay RJ, Cornell RB. Phosphoinositide 3kinase regulates plasma membrane targeting of the Ras-specific exchange factor RasGRP1. J Biol Chem (2011) 286:12712-23. doi: 10.1074/jbc.M110.189605

131. Fuller DM, Zhu M, Song X, Ou-Yang CW, Sullivan SA, Stone JC, et al. Regulation of RasGRP1 function in $\mathrm{T}$ cell development and activation by its unique tail domain. PLoS One (2012) 7:e38796. doi:10.1371/journal. pone.0038796

132. Tazmini G, Beaulieu N, Woo A, Zahedi B, Goulding RE, Kay RJ. Membrane localization of RasGRP1 is controlled by an EF-hand, and by the GEF domain. Biochim Biophys Acta (2009) 1793: 447-61. doi:10.1016/j.bbamcr. 2008.12.019

133. Bivona TG, Perez De Castro I, Ahearn IM, Grana TM, Chiu VK, Lockyer PJ, et al. Phospholipase Cgamma activates Ras on the Golgi apparatus by means of RasGRP1. Nature (2003) 424:694-8. doi:10. 1038/nature01806

134. Izquierdo M, Downward J, Graves JD, Cantrell DA. Role of protein kinase $\mathrm{C}$ in T-cell antigen receptor regulation of p21ras: evidence that two p21ras regulatory pathways coexist in T cells. Mol Cell Biol (1992) 12:3305-12.
135. Hille B. Ion Channels of Excitable Membranes. 3rd ed. Sunderland: Sinauer Associates, Inc (2001).

136. Topham MK, Prescott SM. Diacylglycerol kinase zeta regulates Ras activation by a novel mechanism. J Cell Biol (2001) 152:1135-43. doi:10.1083/jcb.152.6.1135

137. Schneider $H$, Wang $H$, Raab M, Valk E, Smith X, Lovatt M, et al. Adaptor SKAP-55 binds p21 activating exchange factor RasGRP1 and negatively regulates the p21-ERK pathway in T-cells. PLoS One (2008) 3:e1718. doi:10.1371/ journal.pone. 0001718

138. Kosco KA, Cerignoli F, Williams $S$, Abraham RT, Mustelin $\mathrm{T}$ SKAP55 modulates $\mathrm{T}$ cell antigen receptor-induced activation of the Ras-Erk-AP1 pathway by binding RasGRP1. Mol Immunol (2008) 45:510-22. doi:10.1016/j. molimm.2007.05.024

139. Oh-Hora M, Johmura S, Hashimoto A, Hikida M, Kurosaki T. Requirement for Ras guanine nucleotide releasing protein 3 in coupling phospholipase C-gamma2 to Ras in B cell receptor signaling. $J$ Exp Med (2003) 198:1841-51. doi:10.1084/jem.20031547

140. Warnecke N, Poltorak M, Kowtharapu BS, Arndt B, Stone JC, Schraven B, et al. TCR-mediated Erk activation does not depend on Sos and Grb2 in peripheral human T cells. EMBO Rep (2012) 13:38691. doi:10.1038/embor.2012.17

141. Tian T, Harding A, Inder K, Plowman S, Parton RG, Hancock JF. Plasma membrane nanoswitches generate high-fidelity Ras signal transduction. Nat Cell Biol (2007) 9:905-14. doi:10.1038/ncb1615

142. Stefanova I, Hemmer B, Vergelli M, Martin R, Biddison WE, Germain RN. TCR ligand discrimination is enforced by competing ERK positive and SHP-1 negative feedback pathways. Nat Immunol (2003) 4:248-54. doi:10.1038/ni895

143. Bashor CJ, Helman NC, Yan S, Lim WA. Using engineered scaffold interactions to reshape MAP kinase pathway signaling dynamics. Science (2008) 319:1539-43. doi:10.1126/science.1151153

144. Harding A, Tian T, Westbury E, Frische E, Hancock JF. Subcellular localization determines MAP kinase signal output. Curr Biol (2005) 15:869-73. doi:10.1016/j. cub.2005.04.020

145. Prasad A, Zikherman J, Das J, Roose JP, Weiss A, Chakraborty AK. Origin of the sharp boundary that discriminates positive and negative selection of thymocytes. Proc Natl Acad Sci U S A (2009) 106:528-33. doi:10.1073/ pnas. 0805981105

146. Werlen G, Hausmann B, Naeher D, Palmer E. Signaling life and death in the thymus: timing is everything. Science (2003) 299:1859-63. doi:10.1126/science. 1067833

147. Daniels MA, Teixeiro E, Gill J, Hausmann B, Roubaty D, Holmberg $\mathrm{K}$, et al. Thymic selection threshold defined by compartmentalization of Ras/MAPK signalling. Nature (2006) 444:724-9. doi:10. 1038/nature05269

148. McGargill MA, Chen IL, Katayama CD, Pages G, Pouyssegur J, Hedrick SM. Cutting edge: extracellular signal-related kinase is not required for negative selection of developing $\mathrm{T}$ cells. J Immunol (2009) 183:4838-42. doi:10.4049/ jimmunol.0902208

149. Kortum RL, Rouquette-Jazdanian AK, Samelson LE. Ras and extracellular signal-regulated kinase signaling in thymocytes and $\mathrm{T}$ cells. Trends Immunol (2013) 34:25968. doi:10.1016/j.it.2013.02.004

150. Rubio I, Rennert K, Wittig U, Beer K, Durst M, Stang SL, et al. Ras activation in response to phorbol ester proceeds independently of the EGFR via an unconventional nucleotide-exchange factor system in COS-7 cells. Biochem $J$ (2006) 398:243-56. doi:10.1042/ BJ20060160

151. Markegard E, Trager E, Yang CW, Zhang W, Weiss A, Roose JP. Basal LAT-diacylglycerol-RasGRP1 signals in T cells maintain TCRalpha gene expression. PLoS One (2011) 6:e25540. doi:10.1371/journal. pone. 0025540

152. Sugawara T, Moriguchi T, Nishida E, Takahama Y. Differential roles of ERK and p38 MAP kinase pathways in positive and negative selection of $\mathrm{T}$ lymphocytes. Iтmunity (1998) 9:565-74. doi:10.1016/ S1074-7613(00)80639-1

153. Gong Q, Cheng AM, Akk AM Alberola-Ila J, Gong G, Pawson T, et al. Disruption of $\mathrm{T}$ cell signaling networks and development by Grb2 haploid insufficiency. Nat Immunol (2001) 2:29-36. doi:10. $1038 / 83134$

154. Jang IK, Zhang J, Chiang YJ, Kole HK, Cronshaw DG, Zou Y, et al. Grb2 functions at the top of the Tcell antigen receptor-induced tyrosine kinase cascade to control thymic selection. Proc Natl Acad 
Sci U S A (2010) 107:10620-5. doi:10.1073/pnas.0905039107

155. Willingham MC, Pastan I, Shih TY, Scolnick EM. Localization of the src gene product of the Harvey strain of MSV to plasma membrane of transformed cells by electron microscopic immunocytochemistry. Cell (1980) 19:100514. doi:10.1016/0092-8674(80) 90091-4

156. Furth ME, Davis LJ, Fleurdelys B, Scolnick EM. Monoclonal antibodies to the p21 products of the transforming gene of Harvey murine sarcoma virus and of the cellular ras gene family. $J$ Virol (1982) 43:294-304.

157. Myrdal SE, Auersperg N. p21ras. Heterogeneous localization in transformed cells. Exp Cell Res (1985) 159:441-50. doi:10.1016/ S0014-4827(85)80017-3

158. Grand RJ, Smith KJ, Gallimore PH. Purification and characterisation of the protein encoded by the activated human $\mathrm{N}$-ras gene and its membrane localisation. Oncogene (1987) 1:305-14.

159. Matarazzo M, Faraggiana $T$, Donato MF, Paronetto F. Immunocytochemical localization of p21 ras gene product in human hepatoma cell lines and corresponding tumors in athymic mice. J Exp Pathol (1987) 3:305-15.

160. Cox AD, Solski PA, Jordan JD, Der CJ. Analysis of Ras protein expression in mammalian cells. Methods Enzymol (1995) 255:195-220. doi:10.1016/S00766879(95)55023-2

161. Kranenburg O, Verlaan I, Moolenaar WH. Regulating c-Ras function. cholesterol depletion affects caveolin association. Curr Biol (2001) 11:1880-4. doi:10.1016/ S0960-9822(01)00582-6

162. Rubio I. Use of the Ras binding domain of c-Raf for biochemical and live-cell analysis of Ras activation. Biochem Soc Trans (2005) 33:662-3. doi:10. 1042/BST0330662

163. Choy E, Chiu VK, Silletti J, Feoktistov M, Morimoto T, Michaelson D, et al. Endomembrane trafficking of ras: the CAAX motif targets proteins to the ER and Golgi. Cell (1999) 98:69-80. doi:10.1016/S00928674(00)80607-8

164. Rocks O, Peyker A, Bastiaens PI. Spatio-temporal segregation of Ras signals: one ship, three anchors, many harbors. Curr Opin Cell Biol (2006) 18:351-7. doi:10. 1016/j.ceb.2006.06.007
165. Prior IA, Hancock JF. Ras trafficking, localization and compartmentalized signalling. Semin Cell Dev Biol (2012) 23:145-53. doi:10. 1016/j.semcdb.2011.09.002

166. Goodwin JS, Drake KR, Rogers C, Wright L, Lippincott-Schwartz J, Philips MR, et al. Depalmitoylated Ras traffics to and from the Golgi complex via a nonvesicular pathway. J Cell Biol (2005) 170:261-72. doi:10.1083/jcb.200502063

167. Dekker FJ, Rocks O, Vartak N, Menninger S, Hedberg C, Balamurugan R, et al. Small-molecule inhibition of APT1 affects Ras localization and signaling. Nat Chem Biol (2010) 6:449-56. doi: 10.1038/nchembio.362

168. Lorentzen A, Kinkhabwala A, Rocks O, Vartak N, Bastiaens PI. Regulation of Ras localization by acylation enables a mode of intracellular signal propagation. Sci Signal (2010) 3:ra68. doi:10.1126/ scisignal.20001370

169. Rocks O, Gerauer M, Vartak N, Koch S, Huang ZP, Pechlivanis M, et al. The palmitoylation machinery is a spatially organizing system for peripheral membrane proteins. Cell (2010) 141:458-71. doi: 10.1016/j.cell.2010.04.007

170. Duncan JA, Gilman AG. A cytoplasmic acyl-protein thioesterase that removes palmitate from $G$ protein alpha subunits and p21(RAS). J Biol Chem (1998) 273:15830-7. doi:10.1074/jbc.273.25.15830

171. Bivona TG, Quatela SE, Bodemann BO, Ahearn IM, Soskis MJ, Mor $\mathrm{A}$, et al. PKC regulates a farnesylelectrostatic switch on K-Ras that promotes its association with Bcl$\mathrm{XL}$ on mitochondria and induces apoptosis. Mol Cell (2006) 21:48193. doi:10.1016/j.molcel.2006.01. 012

172. Lu A, Tebar F, Alvarez-Moya B, Lopez-Alcala C, Calvo M, Enrich C, et al. A clathrindependent pathway leads to KRas signaling on late endosomes en route to lysosomes. J Cell Biol (2009) 184:863-79. doi:10.1083/ jcb.200807186

173. Perez de Castro I, Bivona TG, Philips MR, Pellicer A. Ras activation in Jurkat $\mathrm{T}$ cells following low-grade stimulation of the T-cell receptor is specific to NRas and occurs only on the Golgi apparatus. Mol Cell Biol (2004) 24:3485-96. doi:10.1128/MCB.24. 8.3485-3496.2004

174. Mor A, Campi G, Du G, Zheng Y, Foster DA, Dustin ML, et al. The lymphocyte functionassociated antigen-1 receptor costimulates plasma membrane Ras via phospholipase D2. Nat Cell Biol (2007) 9:713-9. doi:10.1038/ ncb1592

175. Bivona TG, Quatela S, Philips MR Analysis of Ras activation in living cells with GFP-RBD. Methods Enzymol (2006) 407:128-43. doi: 10.1016/S0076-6879(05)07012-6

176. Quatela SE, Philips MR. Ras signaling on the Golgi. Curr Opin Cell Biol (2006) 18:162-7. doi:10.1016/ j.ceb.2006.02.004

177. Rubio I, Grund S, Song SP, Biskup C, Bandemer S, Fricke $\mathrm{M}$, et al. TCR-induced activation of Ras proceeds at the plasma membrane and requires palmitoylation of N-Ras. J Immuno (2010) 185:3536-43. doi:10.4049/ jimmunol.1000334

178. Chiu VK, Bivona T, Hach A, Sajous JB, Silletti J, Wiener H, et al. Ras signalling on the endoplasmic reticulum and the Golgi. Nat Cell Biol (2002) 4:343-50.

179. Rocks O, Peyker A, Kahms M, Verveer PJ, Koerner C, Lumbierres $\mathrm{M}$, et al. An acylation cycle regulates localization and activity of palmitoylated Ras isoforms. Science (2005) 307:1746-52. doi:10 1126/science.1105654

180. Baldanzi G, Pighini A, Bettio V, Rainero E, Traini S, Chianale F, et al. SAP-mediated inhibition of diacylglycerol kinase alpha regulates TCR-induced diacylglycerol signaling. I Immuno (2011) 187:5941-51. doi:10.4049/ jimmunol.1002476

181. Arndt B, Poltorak M, Kowtharapu BS, Reichardt P, Philipsen L, Lindquist JA, et al. Analysis of TCR activation kinetics in primary human $\mathrm{T}$ cells upon focal or soluble stimulation. J Immunol Methods (2013) 387:276-83. doi: 10.1016/j.jim.2012.11.006

182. Bankaitis VA. Cell biology. Slick recruitment to the Golgi. Science (2002) 295:290-1. doi:10. 1126/science. 1068446

183. Augsten M, Pusch R, Biskup C, Rennert K, Wittig U, Beyer K, et al. Live-cell imaging of endogenous Ras-GTP illustrates predominant Ras activation at the plasma membrane. EMBO Rep (2006) 7: 46-51. doi:10.1038/sj.embor. 7400560

184. Methi T, Ngai J, Vang T, Torgersen KM, Tasken K. Hypophosphorylated TCR/CD3zeta signals through a Grb2-SOS1-Ras pathway in Lck knockdown cells. Eur J
Immunol (2007) 37:2539-48. doi: 10.1002/eji.200636973

185. Baron CL, Malhotra V. Role of diacylglycerol in PKD recruitment to the TGN and protein transport to the plasma membrane. Science (2002) 295:325-8. doi:10. 1126/science. 1066759

186. Jones DR, D'Santos CS, Merida I, Divecha N. T lymphocyte nuclear diacylglycerol is derived from both de novo synthesis and phosphoinositide hydrolysis. Int $J$ Biochem Cell Biol (2002) 34:158-68. doi:10. 1016/S1357-2725(01)00108-X

187. Carrasco S, Merida I. Diacylglycerol, when simplicity becomes complex. Trends Biochem Sci (2007) 32:27-36. doi:10.1016/j. tibs.2006.11.004

188. Almena M, Merida I. Shaping up the membrane: diacylglycerol coordinates spatial orientation of signaling. Trends Biochem Sci (2011) 36:593-603. doi:10.1016/j. tibs.2011.06.005

189. Oancea E, Teruel MN, Quest AF, Meyer T. Green fluorescent protein (GFP)-tagged cysteinerich domains from protein kinase $\mathrm{C}$ as fluorescent indicators for diacylglycerol signaling in living cells. J Cell Biol (1998) 140: 485-98. doi:10.1083/jcb.140.3.485

190. Carrasco S, Merida I. Diacylglycerol-dependent binding recruits PKCtheta and RasGRP1 C1 domains to specific subcellular localizations in living $\mathrm{T}$ lymphocytes. Mol Biol Cell (2004) 15:2932-42. doi:10.1091/mbc.E03-11-0844

191. Spitaler M, Emslie E, Wood CD, Cantrell D. Diacylglycerol and protein kinase $\mathrm{D}$ localization during $\mathrm{T}$ lymphocyte activation. Immunity (2006) 24:535-46. doi:10.1016/j. immuni.2006.02.013

192. Merino E, Sanjuan MA, Moraga I, Cipres A, Merida I. Role of the diacylglycerol kinase alphaconserved domains in membrane targeting in intact $\mathrm{T}$ cells. $J$ Biol Chem (2007) 282:35396-404. doi: 10.1074/jbc.M702085200

193. Espagnolle N, Depoil D, Zaru $\mathrm{R}$, Demeur C, Champagne E, Guiraud M, et al. CD2 and TCR synergize for the activation of phospholipase Cgammal/calcium pathway at the immunological synapse. Int Immunol (2007) 19: 239-48. doi:10.1093/intimm/ dxl141

194. Caloca MJ, Delgado P, Alarcon B, Bustelo XR. Role of chimaerins, a group of Rac-specific GTPase activating proteins, in 
T-cell receptor signaling. Cell Signal (2008) 20:758-70. doi:10. 1016/j.cellsig.2007.12.015

195. Gharbi SI, Rincon E, Avila-Flores A, Torres-Ayuso P, Almena M, Cobos MA, et al. Diacylglycerol kinase zeta controls diacylglycerol metabolism at the immunological synapse. Mol Biol Cell (2011) 22:4406-14. doi:10.1091/ mbc.E11-03-0247

196. Quann EJ, Merino E, Furuta T, Huse M. Localized diacylglycerol drives the polarization of the microtubule-organizing center in T cells. Nat Immunol (2009) 10:627-35. doi:10.1038/ni.1734

197. Monks CR, Freiberg BA, Kupfer H, Sciaky N, Kupfer A. Threedimensional segregation of supramolecular activation clusters in T cells. Nature (1998) 395:82-6. doi:10.1038/25764

198. Villalba M, Bi K, Hu J, Altman Y, Bushway P, Reits E, et al. Translocation of PKC[theta] in T cells is mediated by a nonconventional, PI3-K- and Vav-dependent pathway, but does not absolutely require phospholipase C. J Cell Biol (2002) 157:253-63. doi:10.1083/ jcb.200201097

199. Zugaza JL, Caloca MJ, Bustelo XR. Inverted signaling hierarchy between RAS and RAC in T-lymphocytes. Oncogene (2004) 23:5823-33. doi:10.1038/sj.onc. 1207768

200. Phee H, Abraham RT, Weiss A. Dynamic recruitment of PAK1 to the immunological synapse is mediated by PIX independently of SLP-76 and Vav1. Nat Immunol (2005) 6:608-17. doi:10. 1038/nil199

201. Wennstrom S, Downward J. Role of phosphoinositide 3-kinase in activation of ras and mitogenactivated protein kinase by epidermal growth factor. Mol Cell Biol (1999) 19:4279-88.

202. Rubio I, Wetzker R. A permissive function of phosphoinositide 3-kinase in Ras activation mediated by inhibition of GTPase-activating proteins. Curr Biol (2000) 10:1225-8. doi:10. 1016/S0960-9822(00)00731-4

203. Costello PS, Gallagher M, Cantrell DA. Sustained and dynamic inositol lipid metabolism inside and outside the immunological synapse. Nat Immunol (2002) 3:1082-9. doi:10.1038/ni848

204. Harriague J, Bismuth G. Imaging antigen-induced PI3K activation in T cells. Nat Immunol (2002) 3:1090-6. doi:10.1038/ni847
205. Garcon L, Lacout C, Svinartchouk F, Le Couedic JP, Villeval JL, Vainchenker W, et al. Gfi-1B plays a critical role in terminal differentiation of normal and transformed erythroid progenitor cells. Blood (2005) 105:1448-55. doi:10.1182/ blood-2003-11-4068

206. Randriamampita C, Mouchacca $P$, Malissen B, Marguet D, Trautmann A, Lellouch AC. A novel ZAP-70 dependent FRET based biosensor reveals kinase activity at both the immunological synapse and the antisynapse. PLoS One (2008) 3:e1521. doi:10.1371/ journal.pone.0001521

207. Sperka T, Geissler KJ, Merkel U, Scholl I, Rubio I, Herrlich P, et al. Activation of Ras requires the ERM-dependent link of actin to the plasma membrane. PLoS One (2011) 6:e27511. doi:10.1371/ journal.pone.0027511

208. Martinelli S, Chen EJ, Clarke F, Lyck R, Affentranger S, Burkhardt $\mathrm{JK}$, et al. Ezrin/Radixin/Moesin proteins and flotillins cooperate to promote uropod formation in $\mathrm{T}$ cells. Front Immunol (2013) 4:84. doi:10.3389/fimmu.2013.00084

209. Vanhaesebroeck B, Stephens L, Hawkins P. PI $3 \mathrm{~K}$ signalling: the path to discovery and understanding. Nat Rev Mol Cell Biol (2012) 13:195-203. doi:10.1038/nrm3290

210. Suire S, Condliffe AM, Ferguson GJ, Ellson CD, Guillou $\mathrm{H}$, Davidson K, et al. Gbetagammas and the Ras binding domain of pllogamma are both important regulators of PI(3)Kgamma signalling in neutrophils. Nat Cell Biol (2006) 8:1303-9. doi:10.1038/ ncb1494

211. Gupta S, Ramjaun AR, Haiko P, Wang Y, Warne PH, Nicke B, et al. Binding of ras to phosphoinositide 3-kinase p110alpha is required for ras-driven tumorigenesis in mice. Cell (2007) 129:957-68. doi:10 1016/j.cell.2007.03.051

212. Castellano E, Downward J. RAS interaction with PI3K: more than just another effector pathway. Genes Cancer (2011) 2:261-74. doi:10.1177/1947601911408079

213. Hu Q, Klippel A, Muslin AJ, Fantl WJ, Williams LT. Rasdependent induction of cellular responses by constitutively active phosphatidylinositol-3 kinase. Science (1995) 268:100-2. doi:10. $1126 /$ science. 7701328

214. Lockyer PJ, Wennstrom S, Kupzig S, Venkateswarlu K, Downward J, Cullen PJ. Identification of the ras GTPase-activating protein $\mathrm{GAP} 1(\mathrm{~m})$ as a phosphatidylinositol-3,4,5trisphosphate-binding protein in vivo. Curr Biol (1999) 9:2658. doi:10.1016/S0960-9822(99) 80116-X

215. Tomlinson MG, Kane LP, Su J, Kadlecek TA, Mollenauer MN, Weiss A. Expression and function of Tec, Itk, and Btk in lymphocytes: evidence for a unique role for Tec. Mol Cell Biol (2004) 24:2455-66. doi:10.1128/MCB.24. 6.2455-2466.2004

216. Qin S, Stadtman ER, Chock PB. Regulation of oxidative stressinduced calcium release by phosphatidylinositol 3-kinase and Bruton's tyrosine kinase in B cells. Proc Natl Acad Sci U S A (2000) 97:7118-23. doi:10.1073/ pnas.130198197

217. Varnai $P$, Bondeva $T$, Tamas $P$, Toth B, Buday L, Hunyady L, et al. Selective cellular effects of overexpressed pleckstrinhomology domains that recognize PtdIns(3,4,5)P3 suggest their interaction with protein binding partners. $J$ Cell Sci (2005) 118:4879-88. doi:10.1242/jcs.02606

218. Mohamed AJ, Yu L, Backesjo CM, Vargas L, Faryal R, Aints A, et al. Bruton's tyrosine kinase (Btk): function, regulation, and transformation with special emphasis on the PH domain. Immunol Rev (2009) 228:58-73. doi:10.1111/j. 1600-065X.2008.00741.x

219. Takata M, Kurosaki T. A role for Bruton's tyrosine kinase in B cell antigen receptor-mediated activation of phospholipase C-gamma 2. J Exp Med (1996) 184:31-40. doi:10.1084/jem.184.1.31

220. Saito K, Tolias KF, Saci A, Koon HB, Humphries LA, Scharenberg A, et al. BTK regulates PtdIns-4,5-P2 synthesis: importance for calcium signaling and PI3K activity. Immunity (2003) 19:669-78. doi:10.1016/S10747613(03)00297-8

221. Schaeffer EM, Schwartzberg PL. Tec family kinases in lymphocyte signaling and function. Curr Opin Immunol (2000) 12:282-8. doi:10.1016/S09527915(00)00088-1

222. Gomez-Rodriguez J, Kraus ZJ, Schwartzberg PL. Tec family kinases Itk and Rlk/Txk in T lymphocytes: cross-regulation of cytokine production and T-cell fates. FEBS J (2011) 278:1980-9. doi:10.1111/j.1742-4658.2011 08072.x
223. Honda A, Nogami M, Yokozeki T, Yamazaki M, Nakamura H, Watanabe $\mathrm{H}$, et al. Phosphatidylinositol 4-phosphate 5-kinase alpha is a downstream effector of the small G protein ARF6 in membrane ruffle formation. Cell (1999) 99:521-32. doi:10.1016 S0092-8674(00)81540-8

224. Stephens L, Eguinoa A, Corey S, Jackson T, Hawkins PT. Receptor stimulated accumulation of phosphatidylinositol (3,4,5)trisphosphate by G-protein mediated pathways in human myeloid derived cells. EMBO J (1993) 12:2265-73.

225. Stephens L, Jackson T, Hawkins PT. Synthesis of phosphatidylinositol 3,4,5-trisphosphate in permeabilized neutrophils regulated by receptors and G-proteins. J Biol Chem (1993) 268:17162-72.

226. Hallberg B, Rayter SI, Downward J. Interaction of Ras and Raf in intact mammalian cells upon extracellular stimulation. J Biol Chem (1994) 269:3913-6.

227. Ghosh S, Bell RM. Regulation of Raf-1 kinase by interaction with the lipid second messenger, phosphatidic acid. Biochem Soc Trans (1997) 25:561-5.

228. Rizzo MA, Shome K, Watkins SC, Romero G. The recruitment of Raf- 1 to membranes is mediated by direct interaction with phosphatidic acid and is independent of association with Ras. J Biol Chem (2000) 275: 23911-8. doi:10.1074/jbc M001553200

229. Mollinedo F, Gajate C, Flores I. Involvement of phospholipase $\mathrm{D}$ in the activation of transcription factor AP-1 in human T lymphoid Jurkat cells. J Immunol (1994) 153:2457-69.

230. Reid PA, Gardner SD, Williams DM, Harnett MM. The antigen receptors on mature and immature $\mathrm{T}$ lymphocytes are coupled to phosphatidylcholinespecific phospholipase D activation. Immunology (1997) 90:2506. doi:10.1046/j.1365-2567.1997. 00150.x

231. Esteban LM, Vicario-Abejon C, Fernandez-Salguero P, FernandezMedarde A, Swaminathan $\mathrm{N}$ Yienger $\mathrm{K}$, et al. Targeted genomic disruption of $\mathrm{H}$-ras and $\mathrm{N}$-ras, individually or in combination, reveals the dispensability of both loci for mouse growth and development. Mol Cell Biol (2001) 21:1444-52. doi:10.1128/MCB.21. 5.1444-1452.2001 
232. Iborra S, Soto M, Stark-Aroeira L, Castellano E, Alarcon B, Alonso C, et al. H-ras and N-ras are dispensable for T-cell development and activation but critical for protective Thl immunity. Blood (2011) 117:5102-11. doi:10.1182/blood2010-10-315770

233. Simon JA, Schreiber SL. Grb2 $\mathrm{SH} 3$ binding to peptides from Sos: evaluation of a general model for SH3-ligand interactions. Chem Biol (1995) 2:53-60. doi:10.1016/ 1074-5521(95)90080-2

234. Houtman JC, Yamaguchi H, BardaSaad M, Braiman A, Bowden B, Appella E, et al. Oligomerization of signaling complexes by the multipoint binding of GRB2 to both LAT and SOS1. Nat Struct Mol Biol (2006) 13:798-805. doi:10.1038/ nsmb1133

235. Nag A, Monine MI, Faeder JR, Goldstein B. Aggregation of membrane proteins by cytosolic cross-linkers: theory and simulation of the LAT-Grb2-SOS1 system.
Biophys J (2009) 96:2604-23. doi:10.1016/j.bpj.2009.01.019

236. Sherman E, Barr V, Manley S, Patterson G, Balagopalan L, Akpan I, et al. Functional nanoscale organization of signaling molecules downstream of the $\mathrm{T}$ cell antigen receptor. Immunity (2011) 35:705-20. doi:10.1016/j.immuni. 2011.10.004

237. Zhang W, Trible RP, Zhu M, Liu SK, McGlade CJ, Samelson LE. Association of Grb2, Gads, and phospholipase C-gamma 1 with phosphorylated LAT tyrosine residues. Effect of LAT tyrosine mutations on $\mathrm{T}$ cell angigen receptor-mediated signaling. J Biol Chem (2000) 275:23355-61. doi: 10.1074/jbc.M000404200

238. Lin J, Weiss A. Identification of the minimal tyrosine residues required for linker for activation of $\mathrm{T}$ cell function. $J$ Biol Chem (2001) 276:29588-95. doi: 10.1074/jbc.M102221200

239. Braga VM. GEF without a Dbl domain? Nat Cell Biol (2002)
4:E188-90. doi:10.1038/ncb0802e188

240. Nimnual A, Bar-Sagi D. The two hats of SOS. Sci STKE (2002) 2002:E36. doi:10.1126/stke.2002. 145.pe36

241. Hashimoto A, Okada H, Jiang A, Kurosaki M, Greenberg S, Clark EA, et al. Involvement of guanosine triphosphatases and phospholipase C-gamma2 in extracellular signal-regulated kinase, c-Jun NH2-terminal kinase, and p38 mitogen-activated protein kinase activation by the B cell antigen receptor. J Exp Med (1998) 188:1287-95. doi:10.1084/jem.188.7.1287

242. Ashwell JD. The many paths to p38 mitogen-activated protein kinase activation in the immune system. Nat Rev Immunol (2006) 6:532-40. doi:10.1038/nri1865

Conflict of Interest Statement: The authors declare that the research was conducted in the absence of any commercial or financial relationships that could be construed as a potential conflict of interest.

Received: 02 June 2013; paper pending published: 10 July 2013; accepted: 02 August 2013; published online: 04 September 2013

Citation: Jun JE, Rubio I and Roose JP (2013) Regulation of Ras exchange factors and cellular localization of Ras activation by lipid messengers in $T$ cells. Front. Immunol. 4:239. doi: 10.3389/fimmu.2013.00239

This article was submitted to T Cell Biology, a section of the journal Frontiers in Immunology.

Copyright (c) 2013 Jun, Rubio and Roose. This is an open-access article distributed under the terms of the Creative Commons Attribution License (CC BY). The use, distribution or reproduction in other forums is permitted, provided the original author(s) or licensor are credited and that the original publication in this journal is cited, in accordance with accepted academic practice. No use, distribution or reproduction is permitted which does not comply with these terms. 